\title{
Indacenodithiophene-Based Wide Bandgap Copolymers for High Performance Single-Junction and Tandem Polymer Solar Cells
}

Yunlong Ma, ${ }^{\mathrm{a}, \mathrm{b}}$ Shan-Ci Chen, ${ }^{\mathrm{a}}$ Zaiyu Wang, ${ }^{\mathrm{c}}$ Wei Ma, ${ }^{\mathrm{c}}$ Jin-Yun Wang, ${ }^{\mathrm{a}}$ Zhigang Yin, ${ }^{\mathrm{a}, \mathrm{b}}$ Changquan Tang, ${ }^{\mathrm{a}, \mathrm{b}}$ Dongdong $\mathrm{Cai}^{\mathrm{a}}$ and Qingdong Zheng ${ }^{\mathrm{a}, *}$

a. State Key Laboratory of Structural Chemistry, Fujian Institute of Research on the Structure of Matter, Chinese Academy of Sciences, 155 Yangqiao West Road, Fuzhou, Fujian 350002, China. E-mail: qingdongzheng@fjirsm.ac.cn

b. University of Chinese Academy of Sciences, 19 Yuquan Road, Beijing 100049, China.

c. State Key Laboratory for Mechanical Behavior of Materials, Xi'an Jiaotong University, Xi'an 710049, China.E-mail:msewma@xjtu.edu.cn

Keywords: indacenodithiophene; tandem devices; electron transport layer; fibrous network; polymer solar cells

\section{Abstract}

Two wide bandgap copolymers based on bulky indacenodithiophene (IDT) and alkoxylated benzothiadiazole units (PIDTBTO-T and PIDTBTO-TT) with the thiophene or thieno[3,2-b]thiophene (TT) $\pi$-bridge are designed and synthesized. The effect of $\pi$-bridges on the $\pi-\pi$ packing, optical, carrier transport, nano-sized phase separation and photovoltaic properties of the copolymers are investigated in depth. In comparison with the PIDTBTO-T-based counterpart, the best performance solar cell based on PIDTBTO-TT exhibits a higher power conversion efficiency (PCE) of $8.15 \%$ which is mainly attributed to the formation of a fibrous network for the active layer based on PIDTBTO-TT. Furthermore, when a novel hybrid electron transport layer (PDIN:PFN) is introduced into a tandem solar cell using the PIDTBTO-TT-based device and a PTB7-Th-based device as the bottom and top cell components, respectively, the resulting solar cell exhibits an outstanding PCE of $11.15 \%$ with a large open circuit voltage of $1.70 \mathrm{~V}$. To the best of our knowledge, the PCEs of $8.15 \%$ and $11.15 \%$ are the 
highest values reported to date for the single-junction and tandem solar cells using IDT-based copolymers, respectively. Our results demonstrate that the $\pi$-bridge modulation is effective in adjusting the charge carrier mobility and photovoltaic performance of IDT-based wide bandgap copolymers for single-junction and tandem devices.

\section{Introduction}

Polymer solar cells (PSCs) using p-type conjugated polymers and n-type fullerene derivatives have attracted increasing attention due to their advantages of low cost, light weight, and good flexibility [1] In the past decade, extensive efforts have been devoted to developing new p-type low bandgap conjugated polymers for the photovoltaic application. As a result, significant progresses have been made in this field, and power conversion efficiencies (PCEs) over $10 \%$ have been achieved for both single-junction and tandem PSCs [2]. For single-junction PSCs based on low bandgap copolymers, it is a challenge to simultaneously improve the short circuit current density $\left(J_{S C}\right)$ and open circuit voltage $\left(V_{\text {oc }}\right)$ values because there is a trade-off between high current and large voltage values. As a result, a multi-junction device with a tandem structure is designed as an alternative to broaden the light-harvesting spectra and to increase the $V_{\text {Oc }}$ values of PSCs. For a tandem device, two cells with bulk-heterojunction (BHJ) layers having complementary absorption spectra are usually needed, where a bottom cell utilizes a wide bandgap material and a top cell uses a low bandgap material. Although maximum PCEs of up to $15 \%$ could be expected according to model calculations [3], by now, there are only a couple examples of double-junction tandem PSCs with efficiencies over $11 \%$ [3b-c, $3 \mathrm{~h}$ ], which is mainly attributed to the lack of suitable pair of absorbing materials with different bandgaps and complementary absorption spectra. Specifically, many high performance low bandgap copolymers have been reported in the past decade [2]. However, relatively fewer high performance wide bandgap 
copolymers are available for tandem devices [4], and most of polymer tandem devices have to use poly(3-hexylthiophene) (P3HT, $1.90 \mathrm{eV}$ bandgap, $\mathrm{HOMO}=-5.10 \mathrm{eV}$ ) as the short-wavelength absorbing material, which exhibits a relatively low $V_{\mathrm{Oc}}$ (when blended with $\mathrm{PC}_{71} \mathrm{BM}$ ) [2f, 3d, 3e, 3f]. Another challenge for polymer tandem devices is related to the fact that there are only few interfacial layers available to connect different subcells efficiently [2e, 5]. Therefore, both efficient solution-processed interfacial layers and new wide bandgap materials are needed for high efficiency tandem solar cells.

In designing high performance wide bandgap polymers, a widely adopted strategy is to alternate suitable electron-rich (donor, D) and electron-deficient (acceptor, A) building blocks in the polymer backbone. As both donor and acceptor units are consisted of planar aromatic rings with little conformation flexibility, the connection between donor and acceptor units becomes very important in determining the backbone planarity which subsequently affects the energy levels, bandgaps and charge transport properties of the resulting D-A copolymers. In the past 10 years, in-depth studies on the connection or the $\pi$-bridge between donor and acceptor units are more or less neglected in spite of many donor or acceptor units developed $[1,6]$. Effective $\pi$-bridge modulation strategies should consider the chemical structure difference of the given alternating donor and acceptor units. For the copolymers originated from both five-membered-ring-based donor and acceptor units, usually no $\pi$-bridge is needed. However, for copolymers from a six-membered ring-based unit (such as benzothiadiazole, BT), a suitable five-membered ring-based $\pi$-bridge is required and it will play an important role in determining the performance of the resulting copolymers. $\pi$-Bridges such as thiophene, bithiophene, thieno[3,2-b]thiophene (TT), and other five-membered-ring-based aromatic units can be used for copolymers [1g, 4a, 6, 7]. Among these $\pi$-bridges, TT stands out as an excellent 
candidate due to its linear and extended backbone structure which may reduce the torsional angle between two planar alternating units while not greatly disturbing the electron transfer between donor and acceptor units. With the aforementioned consideration, the incorporation of TT as a $\pi$-bridge into copolymers with some known donor and acceptor units may lead to polymers with unexpected performance, especially in the case of bulky unit-based copolymers. 5,6-Bis(alkoxy)benzo[1,2,5]thiadiazole (BTO) is a typical acceptor unit for wide bandgap copolymers [8a]. We previously explored several series of copolymers using different ladder-type aromatic units as donors and BTO units as acceptors [4e, 8b-c]. Among them, a high PCE of $7.26 \%$ with a $V_{\text {oc }}$ of $0.94 \mathrm{~V}$ was achieved from the alternating copolymer based on diindenocarbazole and 5,6-bis(butoxy)benzo[c][1,2,5] thiadiazole units [8b]. Indacenodithiophene (IDT) is a ladder-type donor unit featuring a coplanar and extended ladder-type framework that can elongate effective $\pi$-conjugation length and facilitate the charge carrier mobility. Since Ko et al. developed the first IDT-based copolymer with a PCE of 4.4\% [9], a large number of IDT-containing copolymers have been synthesized by the copolymerization between various acceptor units and different IDT derivatives [10]. One thing deserves to be mentioned is that the IDT can be also used for the constrution of n-type semiconducting materials as efficient non-fullerene acceptors [11]. Considering the fact that both BTO and IDT are bulky aromatic units with long alkyl chains, a suitable $\pi$-bridge modulation may greatly affect the performance of the copolymers based on them. It is expected that copolymers with a more linear backbone structure and a larger space between the long alkyl chains may show better photovoltaic performance. More importantly, the introduction of $\pi$-bridge into the IDT-BTO polymer backbone may lead to $D-A$ copolymers exhibiting wide bandgaps $[4,7 b]$.

In this context, we report two novel D-A copolymers (PIDTBTO-T, PIDTBTO-TT) based on an IDT 
donor unit and a BTO acceptor unit spaced with thiophene and TT $\pi$-bridges, respectively (Scheme 1). The effects of the $\pi$-bridge on the polymeric curvature, $\pi-\pi$ packing, optical, electrochemical, nano-sized phase separation, carrier transport and photovoltaic properties of the target copolymers are investigated in detail. Conventional PSCs based on the two copolymers as the donors and $[6,6]$-phenyl $C_{71}$-butyric acid methyl ester $\left(P_{71} B M\right)$ as the acceptor have been fabricated. As expected, the copolymer with TT spacers (PIDTBTO-TT) shows a superior PCE up to $7.08 \%$, while PIDTBTO-T exhibits a moderate PCE of $6.40 \%$. After adding a small amount of 1,8 -diiodooctane (DIO) as a processing additive, the PIDTBTO-TT-based device exhibits an increased PCE of $8.15 \%$. For the first time, a hybrid electron transport layer based on poly[(9,9-bis(3'-(N,N-dimethylamino)propyl) -2,7-fluorene)-alt-2,7-(9,9-dioctylfluorene)] (PFN, Figure $\quad$ S1, SI) $[2 e]$ and 2,9-bis(3(dimethylamino)propyl)anthrax[2,1,9-def:6,5,10-d'e'f']diisoquinoline-1,3,8,10(2H,9H)tetraone (PDIN, Figure S1, SI) [5a] is used to fabricated a tandem PSC with PIDTBTO-TT:PC ${ }_{71} \mathrm{BM}$ as the bottom cell component. The best performance tandem device exhibits a high PCE of $11.15 \%$ with a large $V_{\text {oc }}$ of $1.70 \mathrm{~V}, \mathrm{a} J_{\mathrm{sc}}$ of $9.68 \mathrm{~mA} \mathrm{~cm}^{-2}$, and a decent FF of $67.79 \%$. The obtained PCEs of $8.15 \%$ and $11.15 \%$ are the highest values reported to date for single-junction and tandem cells using IDT-based wide bandgap copolymers, respectively.

\section{Results and Discussion}

\subsection{Polymer Synthesis and Characterization}

The copolymers PIDTBTO-T and PIDTBTO-TT were prepared via Stille cross-coupling polymerization between the corresponding monomers (Scheme 1$)$ in toluene using $\mathrm{Pd}_{2}(\mathrm{dba})_{3} / \mathrm{P}(\mathrm{o} \text {-tolyl) })_{3}$ or $\mathrm{Pd}\left(\mathrm{PPh}_{3}\right)_{4}$ catalytic system. Due to the relatively higher reactivity of the BTO-TT monomer in comparison with the BTO-T monomer, a less reactive catalyst, i. e. $\mathrm{Pd}\left(\mathrm{PPh}_{3}\right)_{4}$, was used for PIDTBTO-TT, and a more 
reactive catalyst, i. e. $\operatorname{Pd}_{2}(\mathrm{dba})_{3} / \mathrm{P}(\text { o-tolyl })_{3}$, was used for PIDTBTO-T. Furthermore, different copolymerization times were used to control the molecular weights and to ensure good solubility of the target copolymers. The final copolymers for the device fabrication were from the batches with the highest molecular weights, and with good solubility in chloroform, chlorobenzene, and o-dichlorobenzene (DCB). Before quenching the polymerizations, 2-tributylstannylthiophene and 2-bromothiophene were added sequentially to end-cap the polymer chains with thiophene. This prevents the reactive end groups from acting as charge trapping sites in devices. The crude copolymers were precipitated in methanol, and purified by Soxhlet extraction with methanol, acetone, hexane and dichloromethane in sequence to remove any residual catalyst and low molecular weight oligomers.

The number average molecular weights $\left(M_{\mathrm{n}} \mathrm{S}\right)$ and polydispersity indexes (PDIs) of polymers were measured by gel permeation chromatography (GPC) using 1,2,4-trichlorobenzene as the eluent at $150{ }^{\circ} \mathrm{C}$. The $M_{\mathrm{n}}$ S of PIDTBTO-T and PIDTBTO-TT are 97.5 and $119.9 \mathrm{kDa}$, with PDIs of 2.5 and 1.8 , respectively (Table 1). With six long alkyl chains on every repeat unit, these high molecular weight copolymers still have good solubility in common solvents such as chloroform, chlorobenezene etc. The high molecular weight is desirable because it will help to improve the film-forming ability and the resulting photovoltaic performance. The thermal stability of the copolymers was investigated by thermogravimetric analysis (TGA) (Figure S2, SI). As shown in Figure S2, the two copolymers have good thermal stability with decomposition temperatures (5\% weight loss) over $300{ }^{\circ} \mathrm{C}$ under a nitrogen atmosphere. X-ray diffraction (XRD) (Figure S3, SI) does not show clear diffraction peaks in the range of $2 \theta=0-20^{\circ}$, which indicates that both two copolymers have similar amorphous characteristics as other IDT-based polymers [9-10]. 


\subsection{Optical and Electrochemical Properties}

The UV-Vis absorption spectra of PIDTBTO-T and PIDTBTO-TT in chloroform solution $\left(1 \times 10^{-5} \mathrm{M}\right)$ and thin film are shown in Figure 1 and the detailed optical parameters are summarized in Table 1. In both solution and thin film, PIDTBTO-T and PIDTBTO-TT exhibit very similar absorption characteristics due to their approximate polymer backbones. The higher and lower energy bands (300-500 and 500-700 $\mathrm{nm}$, respectively) are attributed to localized $\pi-\pi^{*}$ transitions and intramolecular D-A charge transfer, respectively. PIDTBTO-TT exhibits red-shifted absorption in solution compared to PIDTBTO-T, with the absorption peak going from 574 to $585 \mathrm{~nm}$. This could be explained by the fact that the higher linearity and extended length of the TT $\pi$-bridge may increase the planarity of the polymer backbone and extend the effective $\pi$-conjugation length which is supported by theoretical studies in the coming section. In going from solution to solid film (Figure 1b), negligible changes are observed for the absorption profiles, except that there are $\sim 18 \mathrm{~nm}$ red-shifted absorption peaks for the thin films. This phenomenon can be assigned to the higher structural organization and more ordered packing induced by the stronger intermolecular interaction in the solid state. The optical bandgaps $\left(E_{\mathrm{g}}{ }^{\text {opt }}\right)$ deduced from the absorption edges ( $\left.\lambda_{\text {edge }}\right)$ of both polymer films are around $1.87 \mathrm{eV}$.

In order to determine the energy levels and electrochemical properties of the copolymers, the cyclic voltammetry (CV) experiments of the copolymers in thin films were conducted. The voltammograms are shown in Figure $1 \mathrm{c}$ and the detailed results are summarized in Table 1 . The onset positions of the $p$-doping process of PIDTBTO-T and PIDTBTO-TT are at $0.57 \mathrm{~V}$ and $0.59 \mathrm{~V}$ versus $\mathrm{Ag} / \mathrm{Ag}^{+}$, corresponding to the highest occupied molecular orbital (HOMO) levels (i.e., ionization potentials) of -5.39 and $-5.41 \mathrm{eV}$, respectively. The lowest unoccupied molecular orbital (LUMO) levels (i.e., electron affinities) for PIDTBTO-T and PIDTBTO-TT are -3.48 and -3.51 eV, respectively, 
according to their onset reduction potentials. The trend of these measured energy levels coincides well with the calculated results by the DFT calculation (Figure S4, SI). The relatively deep HOMO energy level below $-5.39 \mathrm{eV}$ of a copolymer is advantageous to obtain PSCs with high $V_{\text {oc }}$.

\subsection{Conformational Analysis by Calculation}

To gain more insight into the electronic structures of the polymer and, in particular the effect of the $\pi$-bridge unit on the molecular structures and electronic properties, computational studies were performed by density functional theory (DFT, B3LYP/6-311G** level) with a chain length of $n=2$. Hexyl and octyl groups are replaced by methyl groups to simplify the calculation. For both dimers, the HOMO wave functions are delocalized along the polymer backbone, while the LUMO wave functions are more localized at the acceptor units (Figure 2). Meanwhile, a more extended delocalization of the HOMO was observed for PIDTBTO-TT compared to that for PIDTBTO-T. As shown in Figure 2, these two copolymer backbones show similar linear conformation in their top views. However, side views show that PIDTBTO-T has a fairly curved backbone with a torsional angle of $\sim 19^{\circ}$ (Table S1, SI) between the two closest IDT units along the backbone. On the contrary, PIDTBTO-TT shows a higher planarity with a very small torsional angle of $\sim 1.6^{\circ}$, which would facilitate $\pi$-electron delocalization and enhance charge carrier mobility. These results imply that the replacement of the thiophene $\pi$-bridge with the TT unit has a large effect on the geometry of the polymer backbones.

\subsection{Field Effect Transistors}

To evaluate the effect of structural modification of polymers on their hole mobility, organic field-effect transistors (OFETs) based on pristine PIDTBTO-T and PIDTBTO-TT, and with a bottom-gate top-contact device configuration were fabricated on a highly $n$-doped silicon wafer. Typical output and transfer curves are shown in Figure 3, and the parameters are summarized in Table 2. As can be seen from 
their transfer curves, both polymers exhibit typical p-type characteristics. The calculated hole mobilities for PIDTBTO-T and PIDTBTO-TT are $(3.3 \pm 0.3) \times 10^{-3}$ and $(9.1 \pm 0.1) \times 10^{-3} \mathrm{~cm}^{2} \mathrm{~V}^{-1} \mathrm{~s}^{-1}$, respectively. The devices based on both two copolymers exhibit clear on/off behavior which will minimize leakage currents. The hole mobility of PIDTBTO-TT is more than two times higher than that of PIDTBTO-T which is associated with the greater backbone planarity for the former. The results confirm that the insertion of the TT $\pi$-bridge can improve the charge transport property of IDT-based copolymers which may be related to the improved $\pi-\pi$ stacking in thin film. Obviously, compared to PIDTBTO-T, PIDTBTO-TT has some advantages in photovoltaic applications with its higher hole mobility, although these OFET mobilities only represent the charge transport property of pure polymer film in the lateral direction of substrate.

Grazing incident wide-angle X-ray (GIWAXS) [12] is further employed to investigate the molecular packing and crystallinity of pure PIDTBTO-T and PIDTBTO-TT films. The 2D GIWAXS patterns of both polymers are shown in Figure 4a,b and corresponding 1D line-cuts in the in-plane and out-of-plane directions are shown in Figure 4c. Both PIDTBTO-T and PIDTBTO-TT-based films show gentle lamellar (100) peaks in the in-plane and out-of-plane directions and no more other lamellar (h00) peaks are observed. This indicates that both polymers have weak lamellar molecular packing, which corresponds to the amorphous nature of these copolymers. The strong out-of-plane $(010) \pi-\pi$ stacking peaks located at $1.44 \AA^{-1}$ and $1.48 \AA^{-1}$ (d-spacings of $4.36 \AA$ and $4.25 \AA$ ) for PIDTBTO-T and PIDTBTO-TT, respectively, suggest that both polymers have a preferential face-on orientation. The (010) peak intensity of PIDTBTO-TT is higher than that of PIDTBTO-T, and PIDTBTO-TT has a closer $\pi-\pi$ packing distance than PIDTBTO-T. Coherence lengths of (010) peaks estimated by Scherrerequation [13] are $11.5 \AA$ for PIDTBTO-T and $13.1 \AA$ for PIDTBTO-TT, respectively. The improvement of vertical 
$\pi-\pi$ stacking, which is beneficial to charge transport and reducing bimolecular recombination, mainly comes from the better molecular planarity of the PIDTBTO-TT than PIDTBTO-T as evidenced by the theoretical calculation.

\subsection{Photovoltaic Properties of Single Junction Devices}

The photovoltaic properties of both two copolymers were investigated with a conventional device configuration of ITO/PEDOT:PSS/polymer:PC ${ }_{71} \mathrm{BM} / \mathrm{PDIN} / \mathrm{Al}$. Here, PDIN was employed as the cathode interlayer because it can lower the work function of the electrode, allowing higher work-function metals (such as $\mathrm{Al}$ ) to act as the cathode [5a]. $\mathrm{PC}_{71} \mathrm{BM}$ was chosen as the electron acceptor due to its broader and stronger absorption in the visible region, which is complementary to the absorption valley of the copolymers and beneficial for high efficiency PSCs [14]. The active layers were prepared by spin coating the polymer:PC ${ }_{71} \mathrm{BM}$ blends on the top of PEDOT:PSS layer without any further treatment. The measurements were performed under simulated AM 1.5G, $100 \mathrm{~mW} / \mathrm{cm}^{2}$ illumination with an active area of $0.06 \mathrm{~cm}^{2}$. The current density-voltage $(J-V)$ characteristics of these PSCs are shown in Figure $5 \mathrm{a}$, and the parameters of open circuit voltage $\left(V_{\text {oc }}\right)$, short-circuit current $\left(J_{\text {sc }}\right)$, fill factor (FF), and PCE are summarized in Table 3.

Initially, the device performance was optimized through several aspects as follows: i) the polymer: $P C_{71} B M$ blend ratio, ii) the processing solvent (CB: $D C B$ ratio), iii) the active layer thickness (Tables S2-S4, SI). Under the optimal device preparation conditions, the best performance device based on PIDTBTO-T shows a PCE of $6.40 \%$ with $V_{\text {oc }}=0.86 \mathrm{~V}, J_{\mathrm{sc}}=12.36 \mathrm{~mA} \mathrm{~cm}{ }^{-2}$, and FF $=59.90 \%$. In contrast, the best performance device based on PIDTBTO-TT exhibits an improved PCE of $7.08 \%$ with $V_{\mathrm{oc}}=0.88 \mathrm{~V}, \mathrm{~J}_{\mathrm{sc}}=13.21 \mathrm{~mA} \mathrm{~cm}{ }^{-2}$ and $\mathrm{FF}=60.85 \%$. The $V_{\mathrm{oc}}$ of PIDTBTO-TT-based device was higher than that of PIDTBTO-T-based counterpart, which can be attributed to the lower-lying HOMO energy 
level of PIDTBTO-TT. Since the $V_{\text {oc }}$ of a given PSC is related to the energy level difference between the HOMO of the polymer and the LUMO of PC $\mathrm{PC}_{71} \mathrm{BM}$. The increased $\mathrm{I}_{\mathrm{sc}}$ and FF for the PIDTBTO-TT-based device could be the result of optimized morphology and higher hole mobility of the polymer blend. The results demonstrate that inserting the TT $\pi$-bridge into IDT-BTO-based polymer system is an effective strategy to enhance $J_{s c}$ and FF without sacrificing $V_{\text {oc }}$ values of PSCs.

In order to further optimize the photovoltaic performance of the two copolymers through film morphology tuning, 1,8-diiodooctane (DIO) was added into the active layer solutions prior to the spin-coating process (Table S5, SI). When $0.7 \%(\mathrm{v} / \mathrm{v})$ of DIO was added, the $V_{\mathrm{oc}}$ and $J_{\mathrm{sc}}$ of the PIDTBTO-TT-based devices increase to $0.91 \mathrm{~V}$ and $14.77 \mathrm{~mA} \mathrm{~cm}^{-2}$, respectively. As a consequence, the best performance device based on PIDTBTO-TT exhibits an increased PCE of 8.15\%. To the best of our knowledge, this efficiency represents the highest value reported so far for single-junction PSCs based on IDT-containing copolymers. Conversely, the addition of DIO $(0.7 \%$ by volume $)$ to the PIDTBTO-T:PC ${ }_{71} \mathrm{BM}$ blend leads to a drastic drop in PCE $(4.08 \%)$, with a decrease in $V_{\text {oc }}(0.84 \mathrm{~V}), J_{s c}$ (10.28 $\left.\mathrm{mA} \mathrm{cm}{ }^{-2}\right)$, and $\mathrm{FF}(47.22 \%)$. The drop in $V_{\text {oc }}$ can be attributed to the lowered energy of charge-separated state upon the DIO addition [15]. And the decreases in $J_{S C}$ and FF, when DIO was used, could be related to the morphology changes [16].

To ascertain the accuracy of the measurements, external quantum efficiencies (EQEs) of the devices with or without DIO additive were measured and shown in Figure 5b. All the EQE spectra cover a broad spectral response range from 300 to $700 \mathrm{~nm}$, which agree with the absorption spectra of the polymer blends (PIDTBTO-TT:PC ${ }_{71} \mathrm{BM}$ was used as an example, Figure $\mathrm{S} 5, \mathrm{SI}$ ). In this range, the average EQE values of PIDTBTO-T- and PIDTBTO-TT-based devices without DIO are 55\% and 58\%, respectively. After adding DIO, the average EQE values change to $45 \%$ and $65 \%$ for PIDTBTO-T- and 
PIDTBTO-TT-based devices, respectively. The changes in EQE are in agreement with the corresponding changes in $J_{\mathrm{sc}}$ as well as PCE for both copolymers. At the same time, the $J_{\mathrm{sc}}$ values calculated by integrating the EQE data with the AM $1.5 \mathrm{G}$ solar spectrum are close to those obtained from the J-V measurements within $3 \%$ mismatches. For example, for the device based on PIDTBTO-TT with a measured PCE of $8.15 \%$, the calculated $J_{\mathrm{sc}}$ is $14.49 \mathrm{~mA} \mathrm{~cm}{ }^{-2}$, only slightly lower than the measured $J_{\mathrm{sc}}$ of $14.77 \mathrm{~mA} \mathrm{~cm}^{-2}$.

To determine the origin of the observed photovoltaic performance differences between PIDTBTO-TT and PIDTBTO-T and the effect of the solvent additive (DIO) on the active layer, we measured the charge transport properties of the blend films by the space charge limited current (SCLC) method. It should be noted here that the OFET data only represent the lateral mobility at carrier concentration generally greater than that in PSCs. To quantify the carrier mobility perpendicular to the substrate plane, the SCLC measurements were therefore carried out. The structures of hole- and electron-only devices are ITO/PEDOT:PSS/polymer: $\mathrm{PC}_{71} \mathrm{BM} / \mathrm{MoO}_{3} / \mathrm{Au}$ and ITO/ZnO/polymer:PC ${ }_{71} \mathrm{BM} /$ $\mathrm{Ca} / \mathrm{Al}$, respectively. The hole and electron mobilities calculated from the SCLC model are summarized in Table 3, and the corresponding $J-V$ curves under dark condition are shown in Figure $\mathrm{S} 6$ (SI). For the devices without DIO, the hole mobilities are $8.1 \times 10^{-6}$ and $1.7 \times 10^{-5} \mathrm{~cm}^{2} \mathrm{~V}^{-1} \mathrm{~s}^{-1}$ for PIDTBTO-T and PIDTBTO-TT, respectively; and the electron mobilities are $2.2 \times 10^{-5}$ and $3.1 \times 10^{-5} \mathrm{~cm}^{2} \mathrm{~V}^{-1} \mathrm{~s}^{-1}$ for PIDTBTO-T and PIDTBTO-TT, respectively. This explains the better photovoltaic performance, in particular for the higher $J_{s c}$ and FF values of the PIDTBTO-TT-based PSCs compared to the PIDTBTO-T-based devices. After adding DIO as the processing additive, the PIDTBTO-TT:PC ${ }_{71} B M$ film shows a slightly increased hole mobility of $2.3 \times 10^{-5} \mathrm{~cm}^{2} \mathrm{~V}^{-1} \mathrm{~s}^{-1}$, and a similar electron mobility of $3.5 \times 10^{-5} \mathrm{~cm}^{2} \mathrm{~V}^{-1} \mathrm{~s}^{-1}$. Whereas, the PIDTBTO-T:PC ${ }_{71} \mathrm{BM}$ film exhibits significantly decreased hole and 
electron mobilities of $1.2 \times 10^{-6}$ and $7.6 \times 10^{-6} \mathrm{~cm}^{2} \mathrm{~V}^{-1} \mathrm{~s}^{-1}$, respectively. This observation is consistent with the corresponding PCE changes in Table 3. The higher charge carrier mobility and more balanced carrier transport (reduced $\mu_{\mathrm{e}} / \mu_{\mathrm{h}}$ ratio in Table 3) of PIDTBTO-TT-based device than those of PIDTBTO-T-based device after adding DIO are main reasons for the enhanced $J_{\text {sc }}$ and FF of the corresponding device.

To further understand the photovoltaic performance of the two copolymers as well as the additive (DIO) effect on the active layer, the morphologies of the active layers were investigated by transmission electron microscopy (TEM) and atomic force microscopy (AFM). Figure 6 shows the TEM images of the blend films. It can be found that PIDTBTO-T and PIDTBTO-TT blend films without DIO show similar phase separation with domain sizes of $30-50 \mathrm{~nm}$. Thus, the enhanced $J_{\mathrm{sc}}$ and $\mathrm{FF}$ of PIDTBTO-TT-based devices may be contributed to the higher mobility of the active layer. After the addition of DIO, the film morphologies of PIDTBTO-T and PIDTBTO-TT blend films exhibit two distinct conversions. In the case of the PIDTBTO-T blend, the addition of DIO leads to the formation of apparent aggregates with a domain size of more than $100 \mathrm{~nm}$. This kind of morphology will result in inefficient exciton separation and charge transport, and thus worsen the photovoltaic performance of the corresponding device. In contrast, the addition of DIO to the PIDTBTO-TT blend leads to an improved morphology. The relatively big size aggregations of polymer and $\mathrm{PC}_{71} \mathrm{BM}$ diminished and a fibrous network can be clearly observed. Such network is beneficial for exciton separation and charge transport, which is in good agreement with the aforementioned increased PCE and hole/electron mobility. This morphology change trends can also be observed from the AFM images (Figure S7, SI). The addition of DIO to the PIDTBTO-T blend film leads to large size domains, which are not favourable for the transportation of exciton to the donor-acceptor interface. However, the addition of DIO to the 
PIDTBTO-TT blend film leads to more obvious phase separation which is beneficial for charge transportation. At the same time, blend films of PIDTBTO-T and PIDTBTO-TT with PC $_{71}$ BM $_{\text {show }}$ root-mean-square (r.m.s.) surface roughnesses of 0.23 and $0.39 \mathrm{~nm}$, respectively. After the addition of DIO, the roughness of the PIDTBTO-TT:PC ${ }_{71} B M$ film barely changes $(0.38 \mathrm{~nm})$, whereas that for the PIDTBTO-T:PC ${ }_{71} \mathrm{BM}$ film increases to $2.32 \mathrm{~nm}$ in agreement with the formation of large aggregates.

GIWAXS is also used to investigate the molecular packing and crystallinity of blended films with and without DIO. The 2D GIWAXS patterns of the spin-coated films are shown in Figure S8a-d (SI) and corresponding 1D line-cuts in the in-plane and out-of-plane directions are shown in Figure S8e (SI). In general, increased out-of-plane (100) peaks with longer coherence lengths are found for the PIDTBTO-TT blend film with DIO or without DIO in comparison with the PIDTBTO-T blend film, suggesting the better crystallinity of the former copolymer. These results are in agreement with the improved device performance for PIDTBTO-TT in comparison with PIDTBTO-T. However, the 2D GIWAXS result does not reveal significant additive effect on the crystallinity and the packing distance for both copolymer blends.

\subsection{Photovoltaic Properties of Tandem Devices}

To investigate the application of these wide bandgap copolymers in multi-junction PSCS, double-junction tandem cells with a device structure of ITO/PEDOT:PSS/PIDTBTO-TT: $\mathrm{PC}_{71} \mathrm{BM} / \mathrm{PDIN}: \mathrm{PFN} / \mathrm{Al} / \mathrm{MoO}_{3} / \mathrm{PTB7}-\mathrm{Th}: \mathrm{PC}_{71} \mathrm{BM} / \mathrm{PDIN} / \mathrm{Al}$ (Figure 7a) were fabricated as an example. The chemical structures of PTB7-Th, PDIN and PFN are shown in Figure S1 (SI). Here, the low bandgap polymer PTB7-Th was selected as the top cell active material because it has a low bandgap of $1.58 \mathrm{eV}$ with a strong absorption band in the range of $550-780 \mathrm{~nm}$ (Figure $7 \mathrm{~b}$ ) [2c-e], which is somewhat complementary to the absorption profile of PIDTBTO-TT. As shown in Figure 7a, PDIN blended with 
PFN was, for the first time, used as the electron transport layer (ETL) for bottom sub-cell, and molybdenum oxide $\left(\mathrm{MoO}_{3}\right)$ was employed as the hole transport layer for the top sub-cell. Meanwhile, an ultra-thin $\mathrm{Al}(1 \mathrm{~nm})$ film was inserted between the PDIN:PFN and $\mathrm{MoO}_{3}$ layers to establish an ohmic contact. The PDIN:PFN ETL would have combined advantages of the PDIN and PFN layers. For example, the poor film forming properties of PDIN can be improved by blending with the PFN copolymer. At the same time, the presence of PDIN may protect PFN from being damaged by chlorinated solvents. More detailed investigation on this blended ETL is still underway and will be published in due course. The tandem devices were optimized by varying the ETL in the interconnecting layer and the active layer thicknesses. The results show that the devices using PDIN:PFN as the ETL and the active layer with thicknesses of 141 and $85 \mathrm{~nm}$ for bottom and top cells give the highest PCEs (Figures S9-S10, Tables S6-S7, SI). J-V characteristics of the tandem PSCS and corresponding single-junction reference sub-cells are shown in Figure 7c, and the detailed performance parameters are summarized in Table 4.

The best performance tandem cell shows a high PCE of $11.15 \%$ with $J_{\mathrm{sc}}=9.68 \mathrm{~mA} \mathrm{~cm}^{-2}, V_{\text {oc }}=$ 1.70 V, FF $=67.79 \%$. With the same active layers (the same thickness as well), the reference bottom (PIDTBTO-TT:PC ${ }_{71}$ BM) and top (PTB7-Th:PC ${ }_{71} \mathrm{BM}$ ) sub-cells show moderate PCEs of $7.34 \%$ and $7.86 \%$, respectively. Their corresponding EQE spectra are shown in Figure S11 (SI) with small spectral mismatches $(<1 \%)$. It should be noted that the PCE of the reference bottom sub-cell is slightly lower

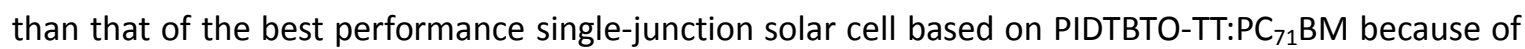
the different thicknesses of the active layer and the different electron transport layers. The $V_{\text {oc }}$ is nearly equal to the sum of the $V_{o c} s$ of the bottom and top cells, and the FF is higher than that of each reference sub-cell, indicating the effectiveness of the interconnecting layer. Similar results have also 
been found in other tandem cells [17]. To further confirm the $I_{\text {sc, }}$ EQEs of the two sub-cells in the tandem PSC were measured using a previously reported method [18]. As shown in Figure 7d, the bottom cell absorbs most of the high energy photons in the range of $300-700 \mathrm{~nm}$ and the maximum photoresponse reached $70 \%$ at $400 \mathrm{~nm}$. On the other hand, the top cell shows external quantum efficiency from 300 to $800 \mathrm{~nm}$, with a maximum EQE of $63 \%$ at $\sim 710 \mathrm{~nm}$. The $J_{\mathrm{sc}}$ values of the bottom and top cells obtained by integrating their EQE curves are 9.39 and $9.33 \mathrm{~mA} \mathrm{~cm}^{-2}$, respectively, which are consistent with the measured $J_{\mathrm{sc}}$ of the tandem PSC under AM 1.5G illumination. As we know, a tandem cell's $J_{\text {sc }}$ is determined by the sub-cell having a lower current. Thus, the higher FF for the tandem device compared to that for each reference sub-cell can be contributed to the quite balanced $J_{\text {sc }}$ values of the bottom and top cells. The PCE of the best performance tandem device reported in this work is comparable to those of the efficient tandem solar cells reported recently [3b, 3c]. Taking into account the fact that the absorption spectra of the two copolymers used in tandem devices overlap in the range of $550-650 \mathrm{~nm}$, we believe that the performance of PIDTBTO-TT-based tandem PSCs can be further improved by using polymers with an even lower bandgap than PTB7-Th.

\section{Conclusions}

In conclusion, we have designed and synthesized two D- $\pi$-A copolymers based on IDT donor unit and BTO acceptor unit with the thiophene or TT $\pi$-bridge (PIDTBTO-T or PIDTBTO-TT). Although the replacement of thiophene $\pi$-bridge in IDT-BTO polymer system with the TT group has little influence on their absorption and energy levels as well as the bandgaps, it plays an important role in tuning the geometry of the polymer backbone as well as the resulting nano-sized phase separation with $\mathrm{PC}_{71} \mathrm{BM}$. The polymer with the TT $\pi$-bridge (PIDTBTO-TT) has a backbone with improved planarity and thereby resulting in its higher hole mobility compared to PIDTBTO-T with the thiophene $\pi$-bridge. 2D GIWAXS 
results further indicate that PIDTBTO-TT has a closer $\pi-\pi$ packing distance as well as a longer coherence length than PIDTBTO-T, which is beneficial to charge transport and reducing bimolecular recombination. Therefore, the PSC based on PIDTBTO-TT:PC 71 BM exhibits a superior PCE of $7.08 \%$, which is higher than that of the device based on PIDTBTO-T:PC ${ }_{71} \mathrm{BM}$. More significantly, after the addition of DIO to PIDTBTO-TT:PC ${ }_{71} \mathrm{BM}$, the PCE increases to $8.15 \%$ with the aid of the fibrous network formed for the active layer. To our knowledge, this is the highest efficiency reported so far for single-junction devices based on IDT-containing copolymers. When PDIN:PFN was used as the electron transport layer, PIDTBTO-TT and PTB7-Th were used as short- and long-wavelength absorbing materials in tandem PSCs, respectively, a highest PCE of $11.15 \%$ with $V_{\mathrm{oc}}=1.70 \mathrm{~V}, \mathrm{~J}_{\mathrm{sc}}=9.68 \mathrm{~mA} \mathrm{~cm}{ }^{-2}$, and $\mathrm{FF}=67.79 \%$ was achieved. The efficiency of $11.15 \%$ is one of the highest values reported to date for polymer tandem solar cells [2f, 3], and it is also the highest value for a tandem device using IDT-based copolymers. At the same time, with the relative large $V_{\text {oc }}$ for the bottom cell, the $V_{\text {oc }}$ of 1.70 $V$ is one of the largest $V_{\text {oc }} s$ for polymer tandem solar cells reported to date. Our results demonstrate that a suitable $\pi$-bridge can be used to adjust the geometries of polymer backbones with bulky alternating units thereby improving the charge carrier mobility and photovoltaic performance of the resulting wide bandgap copolymers. Further, with its relatively large bandgap of $1.87 \mathrm{eV}$ and excellent photovoltaic properties, the $\pi$-bridge modulated copolymers based on IDT are good candidates for short-wavelength absorbing materials in high performance tandem solar cells.

\section{Experimental section}

Materials and Characterization: (4,4,9,9-Tetrakis(4-hexylphenyl)-4,9-dihydro-s-indaceno

[1,2-b:5,6-b']dithiophene-2,7-diyl)bis(trimethylstannane) (IDT) was purchased from Derthon Optoelectronic Materials Science \& Technology Co., Ltd. PTB7-Th was purchased from 1-Material 
Chemscitech Inc. PC 71 BM (99\%) was purchased from American Dye Source Inc. PDIN and PFN were purchased from Suna Tech, Inc. 4,7-Bis(5-bromothiophen-2-yl)-5,6-bis(octyloxy) benzo[c][1,2,5]thiadiazole (BTO-T) [19], 4,7-bis(5-bromothieno[3,2-b]thiophen-2-yl) -5,6-bis(octyl-oxy)benzo[c][1,2,5] thiadiazole (BTO-TT) [6a] were prepared according to the literature procedures. All other chemical reagents were purchased from Aldrich Inc., Aladdin-Reagent Inc., and Adamas-beta Ltd., and used without further purification.

${ }^{1} \mathrm{H}$ NMR spectra were collected on a Bruker AVANCE-400 spectrometer operating at $400 \mathrm{MHz}$ in $\mathrm{CDCl}_{3}$ solutions with tetramethylsilane (TMS) as a proton reference. Gel permeation chromatography (GPC) was conducted in 1,2,4-trichlorobenzene on a Waters 1515 system. Thermogravimetric analysis (TGA) was carried out on a Netzsch STA $449 \mathrm{C}$ instrument at a heating rate of $10{ }^{\circ} \mathrm{C} \cdot \mathrm{min}^{-1}$ under nitrogen flow. The absorption spectra of the copolymers in chloroform solutions $\left(1 \times 10^{-5} \mathrm{M}\right)$ and in thin films were measured by a Lambda 35 UV/vis spectrophotometer. Cyclic voltammetry (CV) was performed on a CHI 604E electrochemical workstation with a three-electrode system in a solution of $0.1 \mathrm{M} \mathrm{Bu}_{4} \mathrm{NPF}_{6}$ in acetonitrile at a scan rate of $100 \mathrm{mV} / \mathrm{s}$. The copolymer films were coated on a Pt plate electrode by dipping the electrode into the corresponding solutions and then drying. A Pt wire was used as the counter electrode, and $\mathrm{Ag} / \mathrm{AgNO}_{3}$ was used as the reference electrode. To obtain electronic energy levels of the polymer films, the HOMO and the LUMO energy levels were estimated by the following equations:

$E_{\text {Hомо }}=-\left(\varphi_{\text {ox }}+4.82\right)(\mathrm{eV})$

$E_{\mathrm{LUMO}}=-\left(\varphi_{\text {red }}+4.82\right)(\mathrm{eV})$

TEM samples were prepared by floating off spin-coated films on PEDOT:PSS coated glass substrates in water, followed by collection with TEM copper mesh grids. TEM images were recorded with a F20 
Tecnai instrument operated at an acceleration voltage of $200 \mathrm{kV}$. The AFM images of the active layers were obtained by an Agilent 5500 at a tapping mode.

Single Junction PSC Fabrication: Indium tin oxide (ITO) glass was cleaned by ultrasonicating sequentially in detergent, water, acetone, and isopropanol for 30 min each and then drying in an oven at $130{ }^{\circ} \mathrm{C}$ overnight. The ITO/glass substrates were subjected to ultraviolet/ozone treatment at room temperature for 15 min. The pre-cleaned ITO substrates were coated with PEDOT:PSS by spin-coating (3000 r.p.m. for $1 \mathrm{~min}$, thickness of $\sim 40 \mathrm{~nm}$ ) and then baked at $140{ }^{\circ} \mathrm{C}$ for $15 \mathrm{~min}$ in air. The active layers (thickness of 101-109 nm) were prepared by spin-coating the polymer:PC $\mathrm{C}_{71} \mathrm{BM}$ blends at 1000 rpm for $1 \mathrm{~min}$ in a glove-box, and the devices were kept at room temperature for $12 \mathrm{~h}$. The methanol solution ( $0.2 \%$ acetic acid) of PDIN at a concentration of $1.5 \mathrm{mg} / \mathrm{mL}$ was deposited on the active layer at $3000 \mathrm{rpm}$ for $30 \mathrm{~s}$, giving a PDIN layer ( 14 nm). Ultimately, about $100 \mathrm{~nm}$ of aluminum was deposited on the top of the PDIN layer to form the negative electrode. The active area of the devices was $6 \mathrm{~mm}^{2}$. After a simple encapsulation by epoxy kits (general purpose, Sigma Aldrich) in glove-box, the PSCs were illuminated through their ITO sides.

Conventional Tandem PSC Fabrication: The device structure of the tandem cell is shown in Figure 7a. The PIDTBTO-TT:PC ${ }_{71} \mathrm{BM}$ active layer was fabricated via the same process as that for the single junction cells, with a thickness of $\sim 140 \mathrm{~nm}$. Then the methanol solution $(0.2 \%$ acetic acid) of PDIN/PFN $(5: 1, \mathrm{w} / \mathrm{w})$ at a concentration of $1.8 \mathrm{mg} / \mathrm{mL}$ was deposited on the active layer at $3000 \mathrm{rpm}$ for $30 \mathrm{~s}$, giving a PDIN/PFN layer $(\sim 15 \mathrm{~nm})$. After that, $1 \mathrm{~nm}$ of $\mathrm{Al}$ and $10 \mathrm{~nm}$ of $\mathrm{MoO}_{3}$ were successively deposited onto the PDIN/PFN layer by thermal evaporation. The PTB7-Th:PC ${ }_{71} B M$ (1:1.5, $\mathrm{w} / \mathrm{w})$ layer was spin-coated onto the $\mathrm{MoO}_{3}$ layer from its mixed solvent of chlorobenzene/ 1,8-diiodoctane $(100: 3, \mathrm{v} / \mathrm{v})$ solution at a spin speed of $1500 \mathrm{rpm}$ for $1 \mathrm{~min}$. Then, a methanol solution 
( $0.2 \%$ acetic acid) of PDIN at a concentration of $1.5 \mathrm{mg} / \mathrm{mL}$ was deposited on the active layer at 3000 rpm for $30 \mathrm{~s}$, giving a PDIN layer ( $14 \mathrm{~nm})$. Finally, the substrates were transferred into the vacuum chamber to finish the device fabrication procedures by depositing $100 \mathrm{~nm}$ of Al. The active area of the devices was $6 \mathrm{~mm}^{2}$. After a simple encapsulation by epoxy kits (general purpose, Sigma Aldrich) in glove-box, the PSCs were illuminated through their ITO sides.

Single Junction or Tandem PSC Characterization: J-V characteristics were measured under AM 1.5 G irradiation $\left(100 \mathrm{~mW} \cdot \mathrm{cm}^{-2}\right)$ on an Oriel sol3A simulator (Newport) with a NREL-certified silicon reference cell using a Keithley 2400 source meter. As shown in Figure S11, the calculated $J_{\text {sc }}$ values for both reference sub-cells from EQE spectra are in good agreement with the values obtained from the $J-V$ measurements within $0.8 \%$ spectral mismatches. Therefore, no mismatch correction was done for the tandem devices. The measurements were carried out by masking all but the active cell area of the fabricated devices. More than 16 devices were analyzed to provide average PCEs for the optimized cells. EQE data was taken using the QE/IPCE Measurement kit (QE-PV-SI) from Newport. To measure the EQE spectra of tandem cells, a chopper and a lock-in amplifier were connected to the Xe lamp as a main light source while a bias light was illuminated to the other sub-cell. The EQE was selectively extracted from each sub-cell in the tandem device using a halogen lamp as the bias light source with a light intensity of about $29.2 \mathrm{~mW} \mathrm{~cm}$. The wavelength of the bias light was controlled with optical filters. The EQEs of the bottom sub-cell and the top sub-cell in the tandem device were obtained using a longpass filter (>720 nm) and a bandpass filter (380-420 nm), respectively. The beam size of the light source is slightly smaller than the device area to avoid errors.

OFET Fabrication and Characterization: Top-contact/bottom-gate OFET devices were fabricated using $\mathrm{Si} / \mathrm{SiO}_{2}$ substrates where $\mathrm{Si}$ and $\mathrm{SiO}_{2}$ were used as the gate electrode and gate dielectric, respectively. 
The substrates were subjected to cleaning by ultrasonication in piranha solution $\left(\mathrm{H}_{2} \mathrm{SO}_{4} / \mathrm{H}_{2} \mathrm{O}_{2}=3 / 1\right)$, deionized water, acetone, and isopropanol, and dried in oven. To optimize device performance, the substrates were modified with octadecyltrimethoxysilane (OTS) to form a self-assembled monolayer. Thin films of the polymers were deposited on the treated substrates by spin coating a polymer solution $(6 \mathrm{mg} / \mathrm{mL})$ in DCB under nitrogen. After polymer thin film deposition, about $40 \mathrm{~nm}$ thick gold electrode was deposited as source and drain contacts using a shadow mask. The OFET devices had a channel length $(L)$ of $300 \mu \mathrm{m}$ and a channel width $(W)$ of $6 \mathrm{~mm}$. The evaluations of the OFETs were carried out in ambient atmosphere using an Agilent $4155 \mathrm{C}$ semiconductor parameter analyzer on a probe station. The carrier mobility, $\mu$, was calculated from the data in the saturated region according to the equation: $\left(I_{d}\right)_{s a t}=(W / 2 L) \mu C_{\mathrm{i}}\left(V_{\mathrm{g}}-V_{\mathrm{th}}\right)^{2}$, where $\left(I_{d}\right)_{\text {sat }}$ is the drain current in the saturated region, $W$ and $L$ are the semiconductor channel width and length, respectively, $C_{\mathrm{i}}\left(C_{\mathrm{i}}=10 \mathrm{nF}\right)$ is the capacitance of the gate dielectric layer, and $V_{\mathrm{g}}$ and $V_{\text {th }}$ are the gate voltage and the threshold voltage, respectively. The saturation region mobilities were calculated from the transfer characteristics of the FETs using the slope derived from the square root of the absolute value of the current as a function of gate voltage between -80 and $-20 \mathrm{~V}$.

Hole- and Electron-Only Device Fabrication and Characterization: Hole-only diodes were fabricated on ITO coated glass with a PEDOT:PSS bottom contact and a $\mathrm{MoO}_{3} / \mathrm{Au}$ top contact. Electron-only diodes were fabricated on ITO coated glass with a $\mathrm{ZnO}$ bottom contact and a $\mathrm{Ca} / \mathrm{Al}$ top contact. The BHJ films were prepared using the same method as that used in the optimal solar cell fabrication. Device areas were $6 \mathrm{~mm}^{2}$. The current density (J) was measured by a Keithley 2440 source measurement unit. The SCLC hole mobilities were calculated according to the following equation: [20] $J=\frac{9}{8} \varepsilon_{r} \varepsilon_{0} \mu \frac{V^{2}}{L^{3}}$ 
where $\varepsilon_{0}$ is the permittivity of free space $\left(8.85 \times 10^{-12} \mathrm{~F} \mathrm{~m}^{-1}\right), \varepsilon_{\mathrm{r}}$ is the dielectric constant of the polymer (assumed to be 3 , which is a typical value for conjugated polymers), $\mu$ is the carrier mobility, $V$ is the voltage drop across the device $\left(V=V_{\mathrm{appl}}-V_{\mathrm{bi}}\right.$, where $V_{\mathrm{appl}}$ is the applied voltage to the device, and $V_{\mathrm{bi}}$ is the built-in voltage due to the difference in work function of the two electrodes), and $L$ is the polymer thickness. The thickness of the film was measured by a Bruker Dektak XT surface profilometer.

GIWAXS Characterization: GIWAXS measurements were performed at beam line 7.3.3 at the Advanced Light Source (ALS). Samples were prepared on Si substrates using identical polymer solutions as those used in FET or OPV devices. The $10 \mathrm{keV} \mathrm{X-ray} \mathrm{beam} \mathrm{was} \mathrm{incident} \mathrm{at} \mathrm{a} \mathrm{grazing} \mathrm{angle} \mathrm{of} 0.11-0.15^{\circ}$, which maximized the scattering intensity from the samples. The scattered X-rays were detected using a Dectris Pilatus $1 \mathrm{M}$ photon counting detector.

Synthesis of PIDTBTO-T: IDT $(0.24 \mathrm{~g}, 0.19 \mathrm{mmol})$ and BTO-T $(0.14 \mathrm{~g}, 0.19 \mathrm{mmol})$ were dissolved in toluene $(20 \mathrm{~mL})$. The mixture was purged with nitrogen for $1 \mathrm{~h}$ at room temperature. After the addition of $\mathrm{Pd}_{2}(\mathrm{dba})_{3}(4 \mathrm{mg})$ and $\mathrm{P}(\mathrm{o} \text {-tolyl })_{3}(10 \mathrm{mg})$, the mixture was heated to reflux for $12 \mathrm{~h}$ under an nitrogen atmosphere. Then, a drop of 2-tributylstannylthiophene was added to the mixture and reacted for $3 \mathrm{~h}$. Finally, two drops of 2-bromothiophene was added to the mixture and reacted overnight to complete the end-capping reaction. The reaction mixture was precipitated into methanol and filtered. The collected precipitate was subjected to Soxhlet extraction with methanol, acetone, hexane, and chloroform for $24 \mathrm{~h}$ each. The chloroform extract was concentrated, and then precipitated into methanol. The target polymer was collected by filtration and dried in vacuo at $50{ }^{\circ} \mathrm{C}$ overnight to give a black solid (0.25 g, 89\%). ${ }^{1} \mathrm{H}$ NMR ( $\left.\mathrm{CDCl}_{3}, 400 \mathrm{MHz}, \mathrm{ppm}\right): 8.49$ (br, 2H), 7.45 (br, 
2H), $7.30(\mathrm{br}, 4 \mathrm{H}), 7.24(\mathrm{br}, 8 \mathrm{H}), 7.14(\mathrm{br}, 8 \mathrm{H}), 4.17(\mathrm{br}, 4 \mathrm{H}), 2.61(\mathrm{br}, 8 \mathrm{H}), 1.98(\mathrm{br}, 4 \mathrm{H}), 1.64(\mathrm{~m}, 8 \mathrm{H})$, $1.51(\mathrm{~m}, 4 \mathrm{H}), 1.34(\mathrm{~m}, 40 \mathrm{H}), 0.90(\mathrm{~m}, 18 \mathrm{H}) . \mathrm{GPC}: M_{\mathrm{n}}=97.5 \mathrm{kDa}, \mathrm{PDI}=2.5$.

Synthesis of PIDTBTO-TT: IDT $(0.31 \mathrm{~g}, 0.25 \mathrm{mmol})$ and BTO-TT $(0.21 \mathrm{~g}, 0.25 \mathrm{mmol})$ were dissolved in toluene $(20 \mathrm{~mL})$. The mixture was purged with nitrogen for $1 \mathrm{~h}$ at room temperature. After the addition of $14.5 \mathrm{mg}$ of $\mathrm{Pd}\left(\mathrm{PPh}_{3}\right)_{4}$, the mixture was heated to reflux for $9 \mathrm{~h}$ under an nitrogen atmosphere. Then, a drop of 2-tributylstannylthiophene was added to the mixture and reacted for $3 \mathrm{~h}$. Finally, two drops of 2-bromothiophene was added to the mixture and reacted overnight to complete the end-capping reaction. The reaction mixture was precipitated into methanol and filtered. The collected precipitate was subjected to Soxhlet extraction with methanol, acetone, hexane, dichloromethane and chloroform for $24 \mathrm{~h}$ each. The chloroform extract was concentrated and then precipitated into methanol. The target polymer was collected by filtration and dried in vacuo at $50{ }^{\circ} \mathrm{C}$ overnight to give a black solid (0.28 g, 72\%). ${ }^{1} \mathrm{H} \mathrm{NMR}\left(\mathrm{CDCl}_{3}, 400 \mathrm{MHz}, \mathrm{ppm}\right): 8.84(\mathrm{br}, 2 \mathrm{H}), 7.45(\mathrm{br}$, 2H), $7.41(\mathrm{br}, 4 \mathrm{H}), 7.25-7.13(\mathrm{~m}, 16 \mathrm{H}), 4.18(\mathrm{br}, 4 \mathrm{H}), 2.61(\mathrm{br}, 8 \mathrm{H}), 2.03(\mathrm{br}, 4 \mathrm{H}), 1.59(\mathrm{~m}, 8 \mathrm{H}), 1.51(\mathrm{~m}$, 4H), $1.33(\mathrm{~m}, 4 \mathrm{H}), 0.91(\mathrm{~m}, 18 \mathrm{H}) . \mathrm{GPC}: M_{\mathrm{n}}=119.9 \mathrm{kDa}, \mathrm{PDI}=1.8$.

\section{Acknowledgements}

This work was supported by the National Natural Science Foundation of China (Nos. U1605241, 61325026, 51561165011), the Strategic Priority Research Program of the Chinese Academy of Sciences (No. XDB20000000), and the CAS/SAFEA International Partnership Program for Creative Research Teams. The GIWAXS characterization is supported by the Director, Office of Science, Office of Basic Energy Sciences, of the U.S. Department of Energy under Contract No. DE-AC02-05CH11231.

\section{References}


[1] (a) J. Chen, Y. Cao, Acc. Chem. Res. 42 (2009) 1709-1718; (b) G. Li, R. Zhu, Y. Yang, Nat Photonics 6 (2012) 153-161; (c) Y. Li, Acc. Chem. Res. 45 (2012) 723-733; (d) L. Ye, S. Q. Zhang, L. J. Huo, M. J. Zhang, J. H. Hou, Acc. Chem. Res. 47 (2014) 1595-1603; (e) J.-S. Wu, S.-W. Cheng, Y.-J. Cheng, C.-S. Hsu, Chem. Soc. Rev. 44 (2015) 1113-1154; (f) L. Lu, T. Zheng, Q. Wu, A. M. Schneider, D. Zhao, L. Yu, Chem. Rev. 115 (2015) 12666-12731; (g) W. Li, K. H. Hendriks, M. M. Wienk, R. A. J. Janssen, Acc. Chem. Res. 49 (2016) 78-85.

[2] (a) Y. Liu, J. Zhao, Z. Li, C. Mu, W. Ma, H. Hu, K. Jiang, H. Lin, H. Ade, H. Yan, Nat. Commun. 5 (2014) 5293; (b) Y. Liu, Z. A. Page, T. P. Russell, T. Emrick, Angew. Chem. Int. Ed. 54 (2015) 11485-11489; (c) X. Ouyang, R. Peng, L. Ai, X. Zhang and Z. Ge, Nat. Photonics 9 (2015) 520-524; (d) J.-D. Chen, C. Cui, Y.-Q. Li, L. Zhou, Q.-D. Ou, C. Li, Y. Li, J.-X. Tang, Adv. Mater. 27 (2015) 1035-1041; (e) Z. C. He, B. Xiao, F. Liu, H. B. Wu, Y. L. Yang, S. Xiao, C. Wang, T. P. Russell, Y. Cao, Nat. Photonics 9 (2015) 174-179; (f) J. B. You, L. T. Dou, K. Yoshimura, T. Kato, K. Ohya, T. Moriarty, K. Emery, C.-C. Chen, J. Gao, G. Li, Y. Yang, Nat. Commun. 4 (2013) 1446; (g) N. Li, C. J. Brabec, Energy Environ. Sci. 8 (2015) 2902-2909; (h) A. R. b. M. Yusoff, D. Kim, H. P. Kim, F. K. Shneider, W. J. da Silva, J. Jang, Energy Environ. Sci. 8 (2015) 303-316.

[3] (a) F. Guo, N. Li, F. W. Fecher, N. Gasparini, C. O. R. Quiroz, C. Bronnbauer, Y. Hou, V. V. Radmilovic, V. R. Radmilovic, E. Spiecker, K. Forberich, C. J. Brabec, Nat. Commun. 6 (2015) 7730; (b) H. Q. Zhou, Y. Zhang, C. K. Mai, S. D. Collins, G. C. Bazan, T. Q. Nguyen, A. J. Heeger, Adv. Mater. 27 (2015) 1767-1773; (c) K. Zhang, K. Gao, R. Xia, Z. Wu, C. Sun, J. Cao, L. Qian, W. Li, S. Liu, F. Huang, X. Peng, L. Ding, H.-L. Yip, Y. Cao, Adv. Mater. 28 (2016) 4817-4823; (d) O. Adebanjo, B. Vaagensmith, Q. Qiao, J. Mater. Chem. A 2 (2014) 10331-10349; (e) N. Li, D. Baran, K. Forberich, F. Machui, T. Ameri, M. Turbiez, M. Carrasco-Orozco, M. Drees, A. Facchetti, F. C. Krebs, C. J. Brabec, Energy Environ. Sci. 6 (2013) 3407-3413; (f) J. Y. Kim, K. Lee, N. E. Coates, D. Moses, T. Q. Nguyen, M. Dante, A. J. Heeger, Science 317 (2007) 222-225; (g) C.-Y. Chang, L. Zuo, H.-L. Yip, C.-Z. Li, Y. Li, C.-S. Hsu, Y.-J. Cheng, H. Chen, A. K. Y. Jen, Adv. Energy Mater. 4 (2014) 1301645; (h) Z. Zheng, S. Zhang, J. Zhang, Y. Qin, W. Li, R. Yu, Z. Wei, J. Hou, Adv. Mater. 28 (2016) 5133-5138; (i) L. Dou, J. You, J. Yang, C.-C. Chen, Y. He, S. Murase, T. Moriarty, K. Emery, G. Li, Y. Yang, Nat. Photonics 6 (2012) 180-185. 
[4] (a) Y. Ma, Z. Kang, Q. Zheng, J. Mater. Chem. A 5 (2017) DOI: 10.1039/C6TA09325F; (b) S. C. Price, A. C. Stuart, L. Yang, H. Zhou, W. You, J. Am. Chem. Soc. 133 (2011) 4625-4631; (c) Y. Dong, X. W. Hu, C. H. Duan, P. Liu, S. J. Liu, L. Y. Lan, D. C. Chen, L. Ying, S. J. Su, X. Gong, F. Huang, Y. Cao, Adv. Mater. 25 (2013) 3683-3688; (d) C. Cabanetos, A. El Labban, J. A. Bartelt, J. D. Douglas, W. R. Mateker, J. M. J. Frechet, M. D. McGehee, P. M. Beaujuge, J. Am. Chem. Soc., 135 (2013) 4656-4659; (e) Y. Ma, Q. Zheng, L. Wang, D. Cai, C. Tang, M. Wang, Z. Yin, S.-C. Chen, J. Mater. Chem. A 2 (2014) 13905-13915; (f) J. W. Jung, F. Liu, T. P. Russell, W. H. Jo, Adv. Energy Mater. 5 (2015) 1503902; (g) M. Wang, D. Cai, Z. Yin, S.-C. Chen, C.-F. Du, Q. Zheng, Adv. Mater. 28 (2016) 3359-336; (f) M. Wang, Z. Wang, W. Ma, S.-C. Chen, Q. Zheng, Adv. Electron. Mater. 2 (2016) 1600340.

[5] (a) Z.-G. Zhang, B. Qi, Z. Jin, D. Chi, Z. Qi, Y. Li, J. Wang, Energy Environ. Sci. 7 (2014) 1966-1973; (b) Z. Yin, J. Wei, Q. Zheng, Adv. Sci. 3 (2016) 1500362.

[6] (a) X. Wang, Y. Sun, S. Chen, X. Guo, M. Zhang, X. Li, Y. Li, H. Wang, Macromolecules 45 (2012) 1208-1216; (b) X. Guo, M. J. Zhang, L. J. Huo, F. Xu, Y. Wu, J. H. Hou, J. Mater. Chem. 22 (2012) 21024-21031; (c) J. J. Intemann, K. Yao, Y.-X. Li, H.-L. Yip, Y.-X. Xu, P.-W. Liang, C.-C. Chueh, F.-Z. Ding, X. Yang, X. Li, Y. Chen, A. K. Y. Jen, Adv. Funct. Mater. 24 (2014) 1465-1473; (d) G. Zuo, Z. Li, M. Zhang, X. Guo, Y. Wu, S. Zhang, B. Peng, W. Wei, J. Hou, Polym. Chem. 5 (2014) 1976-1981.

[7] (a) M. H. Chen, J. Hou, Z. Hong, G. Yang, S. Sista, L. M. Chen, Y. Yang, Adv. Mater. 21 (2009) 4238-4242; (b) Q. Zheng, B. J. Jung, J. Sun, H. E. Katz, J. Am. Chem. Soc. 132 (2010) 5394-5404; (c) K. Li, Z. Li, K. Feng, X. Xu, L. Wang, Q. Peng, J. Am. Chem. Soc. 135 (2013) 13549-13557.

[8] (a) R. P. Qin, W. W. Li, C. H. Li, C. Du, C. Veit, H. F. Schleiermacher, M. Andersson, Z. S. Bo, Z. P. Liu, O. Inganas, U. Wuerfel, F. L. Zhang, J. Am. Chem. Soc. 131 (2009) 14612-14613; (b) L. Wang, D. Cai, Z. Yin, C. Tang, S.-C. Chen and Q. Zheng, Polym. Chem. 5 (2014) 6847-6856; (c) Y. Ma, Q. Zheng, Z. Yin, D. Cai, S.-C. Chen, C. Tang, Macromolecules, 46 (2013) 4813-4821.

[9] C.-P. Chen, S.-H. Chan, T.-C. Chao, C. Ting, B.-T. Ko, J. Am. Chem. Soc. 130 (2008) $12828-12833$.

[10] (a) Y. Zhang, J. Zou, H.-L. Yip, K.-S. Chen, D. F. Zeigler, Y. Sun, A. K. Y. Jen, Chem. Mater., 23 (2011) 2289-2291; (b) M. Zhang, X. Guo, X. Wang, H. Wang, Y. Li, Chem. Mater. 23 (2011) 
4264-4270; (c) X. Guo, M. Zhang, J. Tan, S. Zhang, L. Huo, W. Hu, Y. Li, J. Hou, Adv. Mater. 24 (2012) 6536-6541; (d) H. Bronstein, J. M. Frost, A. Hadipour, Y. Kim, C. B. Nielsen, R. S. Ashraf, B. P. Rand, S. Watkins, I. McCulloch, Chem. Mater. 25 (2013) 277-285; (e) M. Wang, X. Hu, L. Liu, C. Duan, P. Liu, L. Ying, F. Huang, Y. Cao, Macromolecules 46 (2013) 3950-3958; (f) D. Liu, L. Sun, Z. Du, M. Xiao, C. Gu, T. Wang, S. Wen, M. Sun, R. Yang, RSC Adv. 4 (2014) 37934-37940; (g) L. Zuo, C.-Y. Chang ,C.-C. Chueh, S. Zhang, H. Li, A. K. Y. Jen, H. Chen, Energy Environ. Sci. 8 (2015) 1712-1718.

[11] (a) Y. Lin, J. Wang, Z. G. Zhang, H. Bai, Y. Li, D. Zhu, X. Zhan, Adv. Mater. 27 (2015) 1170-1174; (b) Y. Lin, Q. He, F. Zhao, L. Huo, J. Mai, X. Lu, C.-J. Su, T. Li, J. Wang, J. Zhu, Y. Sun, C. Wang, X. Zhan, J. Am. Chem. Soc. 138 (2016) 2973-2976.

[12] (a) A. A. Y. Guilbert, J. M. Frost, T. Agostinelli, E. Pires, S. Lilliu, J. E. Macdonald, J. Nelson, Chem. Mater. 26 (2014) 1226-1233; (b) A. Hexemer, W. Bras, J. Glossinger, E. Schaible, E. Gann, R. Kirian, A. MacDowell, M. Church, B. Rude, H. Padmore, presented at 14th International Conference on Small-Angle Scattering (SASO9), Oxford, ENGLAND, Sep 13-18, 2009.

[13] (a) D.-M. Smilgies, J. Appl. Crystallogr. 46 (2013) 286; (b) R. Noriega, J. Rivnay, K. Vandewal, F. P. Koch, N. Stingelin, P. Smith, M. F. Toney, A. Salleo, Nat. Mater. 12 (2013) 1038-1044.

[14] M. M. Wienk, J. M. Kroon, W. J. H. Verhees, J. Knol, J. C. Hummelen, P. A. van Hal, R. A. J. Janssen, Angew. Chem. Int. Ed. 115 (2003) 3493-3497.

[15] D. D. Nuzzo, A. Aguirre, M. Shahid, V. S. Gevaerts, S. C. Meskers, R. A. Janssen, Adv. Mater. 22 (2010) 4321-4324.

[16] (a) C. B. Nielsen, R. S. Ashraf, N. D. Treat, B. C. Schroeder, J. E. Donaghey, A. J. P. White, N. Stingelin and I. McCulloch, Adv. Mater. 27 (2015) 948-953; (b) H. Zhong, Z. Li, F. Deledalle, E. C. Fregoso, M. Shahid, Z. Fei, C. B. Nielsen, N. Yaacobi-Gross, S. Rossbauer, T. D. Anthopoulos, J. R. Durrant and M. Heeney, J. Am. Chem. Soc. 135 (2013) 2040-2043; (c) N. Wang, Z. Chen, W. Wei and Z. Jiang, J. Am. Chem. Soc. 135 (2013) 17060-17068.

[17] (a) A. Martinez-Otero, Q. Liu, P. Mantilla-Perez, M. M. Bajo, J. Martorell, J. Mater. Chem. A 3 (2015) 10681; (b) Y. Liu, C.-C. Chen, Z. Hong, J. Gao, Y. Yang, H. Zhou, L. Dou, G. Li, Sci. Rep. 3 (2013) 3356. 
[18] J.-H. Kim, J. B. Park, F. Xu, D. Kim, J. Kwak, A. C. Grimsdale, D.-H. Hwang, Energy Environ. Sci. 7 (2014) 4118-4131.

[19] S. Zeng, L. Yin, C. Ji, X. Jiang, K. Li, Y. Li, Y. Wang, Chem. Commun. 48 (2012) 10627-10629.

[20] G. G. Malliaras, J. R. Salem, P. J. Brock, C. Scott, Phys. Rev. B 58 (1998) 13411-13414. 
Table 1. Summary of the molecular weights, optical, and electrochemical properties of the copolymers

\begin{tabular}{|c|c|c|c|c|c|c|c|}
\hline Polymer & $\begin{array}{c}M_{n} \\
(\mathrm{kDa})\end{array}$ & PDI & $\begin{array}{l}\lambda_{\max }(\mathrm{nm}) \\
\text { in } \mathrm{CHCl}_{3}\end{array}$ & $\begin{array}{l}\lambda_{\max }(\mathrm{nm}) \\
\text { in film }\end{array}$ & $\begin{array}{l}E_{g}^{o p t} \\
(e V)^{a}\end{array}$ & $\begin{array}{r}\mathrm{HOMO} \\
(\mathrm{eV})^{\mathrm{b}}\end{array}$ & $\begin{array}{l}\text { LUMO } \\
(\mathrm{eV})^{\mathrm{c}}\end{array}$ \\
\hline PIDTBTO-T & $97 \cdot 5$ & 2.5 & 574 & 593 & 1.87 & $-5 \cdot 39$ & -3.48 \\
\hline PIDTBTO-TT & 119.9 & 1.8 & 585 & 602 & 1.87 & -5.41 & $-3 \cdot 51$ \\
\hline \multicolumn{8}{|c|}{$\begin{array}{l}\text { Estimated from the onset of the absorption spectra of thin films; }{ }^{\mathrm{b}} E_{\mathrm{HOMO}}=-\left(\varphi_{\mathrm{ox}}+4.82\right) \mathrm{eV} ;{ }^{\mathrm{c}} E_{\mathrm{LUMO}}= \\
-\left(\varphi_{\text {red }}+4.82\right)(\mathrm{eV})\end{array}$} \\
\hline
\end{tabular}


Table 2. Mobilities, on-off current ratios, and threshold voltages of OFETs based on the copolymers

\begin{tabular}{lccc}
\hline Polymer & $\mu\left(\mathrm{cm}^{2} \mathrm{v}^{-1} \mathrm{~s}^{-1}\right)^{\mathrm{a}}$ & $I_{\text {on }} / I_{\text {off }}^{\mathrm{b}}$ & $V_{\mathrm{t}}(\mathrm{V})^{\mathrm{c}}$ \\
\hline PIDTBTO-T & $(3.3 \pm 0.3) \times 10^{-3}$ & $10^{3}$ & $-(3-10)$ \\
PIDTBTO-TT & $(9.1 \pm 0.1) \times 10^{-3}$ & $10^{3}$ & $-(4-10)$ \\
${ }^{\mathrm{a}}$ Hole mobility measured at & $V_{\mathrm{D}}=-80 \mathrm{~V} ;{ }^{\mathrm{b}}$ Current on to off ratio; ${ }^{\mathrm{c}}$ Threshold voltage. \\
\hline
\end{tabular}


Table 3. Photovoltaic properties of the PSCs based on PIDTBTO-T and PIDTBTO-TT under AM 1.5G, $100 \mathrm{~mW} / \mathrm{cm}^{2}$

\begin{tabular}{|c|c|c|c|c|c|c|c|c|}
\hline Polymer & DIO (v/v) & $V_{\text {oc }}(\mathrm{V})$ & $J_{s c}\left(m A / c^{2}\right)$ & $\begin{array}{l}F F \\
(\%)\end{array}$ & $\operatorname{PCE}(\%)^{a}$ & $\begin{array}{c}\mu_{\mathrm{h}}\left(\mathrm{cm}^{2} \mathrm{v}^{-1}\right. \\
\left.\mathrm{s}^{-1}\right)^{\mathrm{b}}\end{array}$ & \multicolumn{2}{|c|}{$\mu_{\mathrm{e}}\left(\mathrm{cm}^{2} \mathrm{v}^{-1} \mathrm{~s}^{-1}\right)^{\mathrm{b}} \mu_{\mathrm{e}} / \mu_{\mathrm{h}}$ ratio } \\
\hline PIDTBTO-T & $0 \%$ & 0.86 & 12.36 & 59.90 & $\begin{array}{c}6.40 \\
(6.31 \pm 0.12)\end{array}$ & $(8.1 \pm 0.1) \times 10^{-6}$ & $(2.2 \pm 0.1) \times 10^{-5}$ & 2.7 \\
\hline PIDTBTO-T & $0.7 \%$ & 0.84 & 10.28 & 47.22 & $\begin{array}{c}4.08 \\
(4.01 \pm 0.18)\end{array}$ & $(1.2 \pm 0.4) \times 10^{-6}$ & $(7.6 \pm 0.6) \times 10^{-6}$ & 6.3 \\
\hline PIDTBTO-TT & $0 \%$ & 0.88 & 13.21 & 60.85 & $\begin{array}{c}7.08 \\
(6.92 \pm 0.25)\end{array}$ & $(1.7 \pm 0.2) \times 10^{-5}$ & $(3.1 \pm 0.2) \times 10^{-5}$ & 1.8 \\
\hline PIDTBTO-TT & $0.7 \%$ & 0.91 & 14.77 & 60.86 & $\begin{array}{c}8.15 \\
(7.91 \pm 0.24)\end{array}$ & $(2.3 \pm 0.1) \times 10^{-5}$ & $(3.5 \pm 0.1) \times 10^{-5}$ & 1.5 \\
\hline $\begin{array}{l}{ }^{\mathrm{a}} \text { The averag } \\
\text { measured by }\end{array}$ & $\begin{array}{l}\text { CEs in the } \\
\text { e SCLC me }\end{array}$ & $\begin{array}{l}\text { arenthe } \\
\text { hod. }\end{array}$ & $s$ are based o & $16 \mathrm{de}$ & ${ }^{\mathrm{b}}$ The avera & mobilities are & sed on 8 devices & \\
\hline
\end{tabular}


Table 4. Photovoltaic performances of tandem PSCs and reference sub-cells

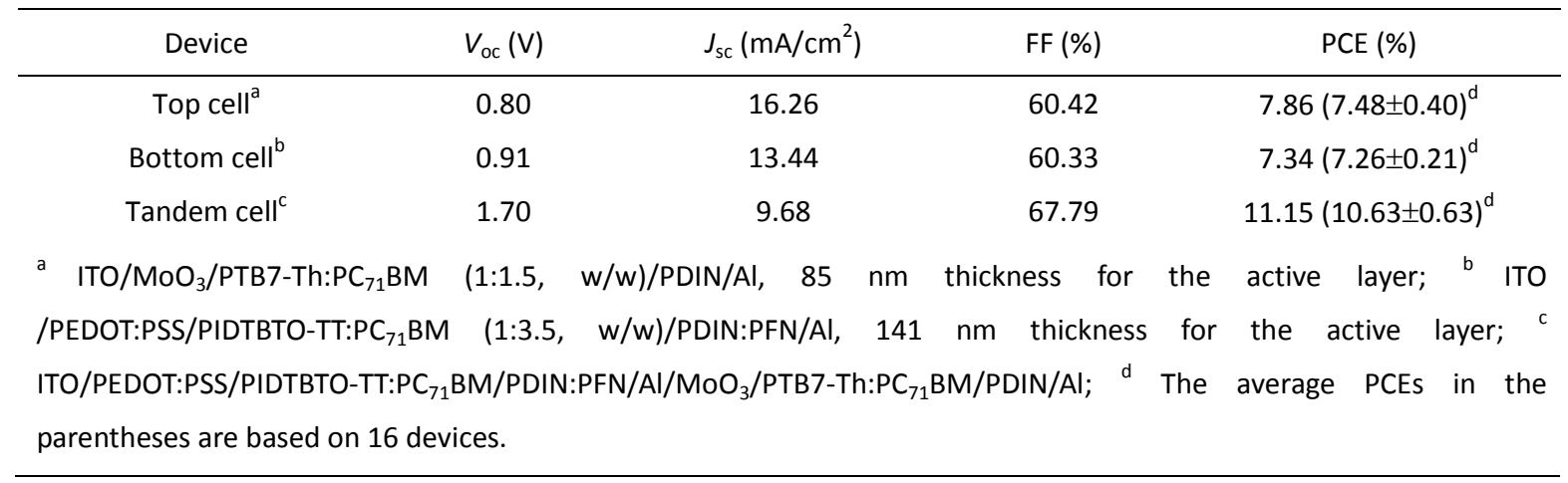


Scheme 1. Synthesis of target IDT-based wide bandgap copolymers. 
a)

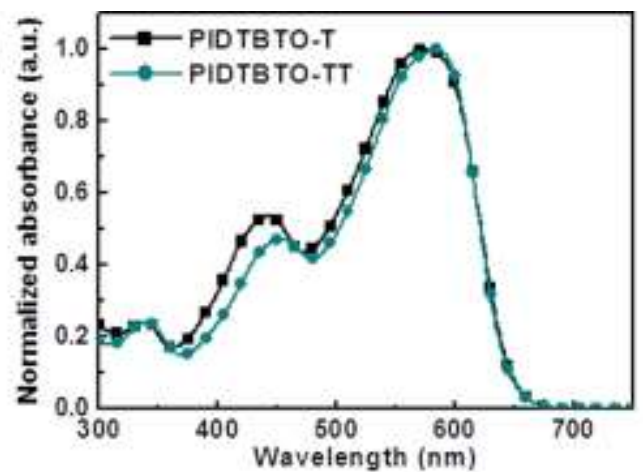

c)

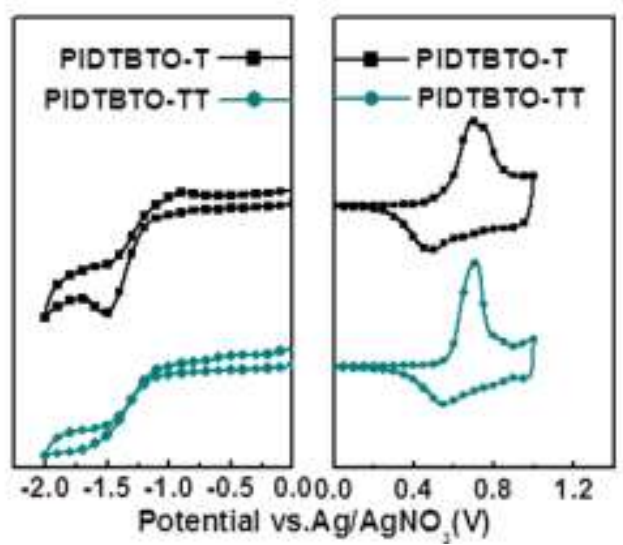

b)

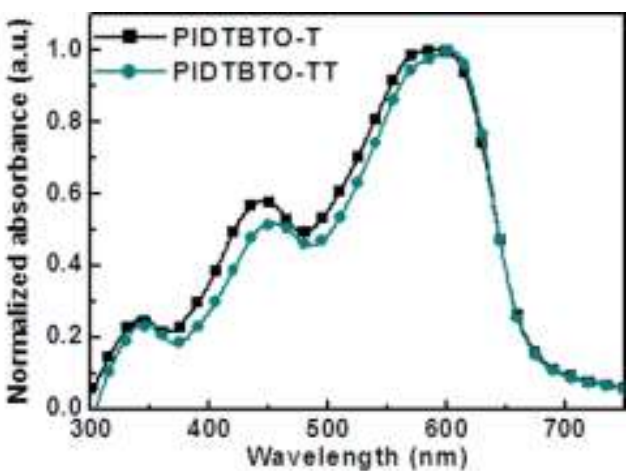

d)

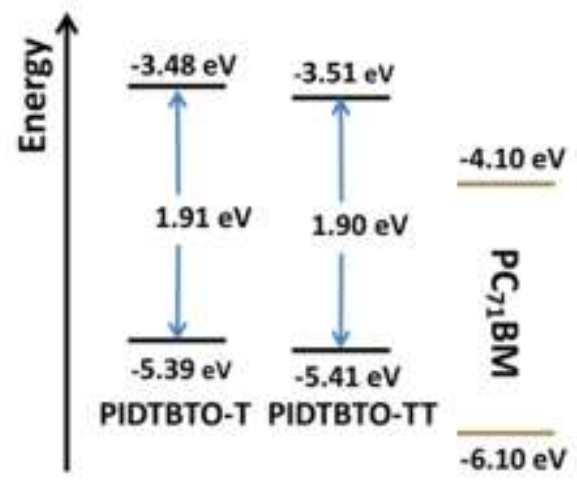

Figure 1. UV-vis absorption spectra in a) solution and b) thin film; c) cyclic voltammograms and d) energy level diagram of the copolymers. 


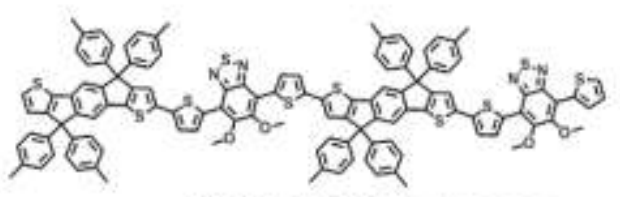

IDTBTO-T dimer

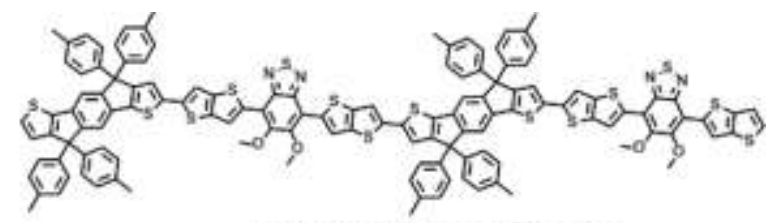

IDTBTO-TT dimer

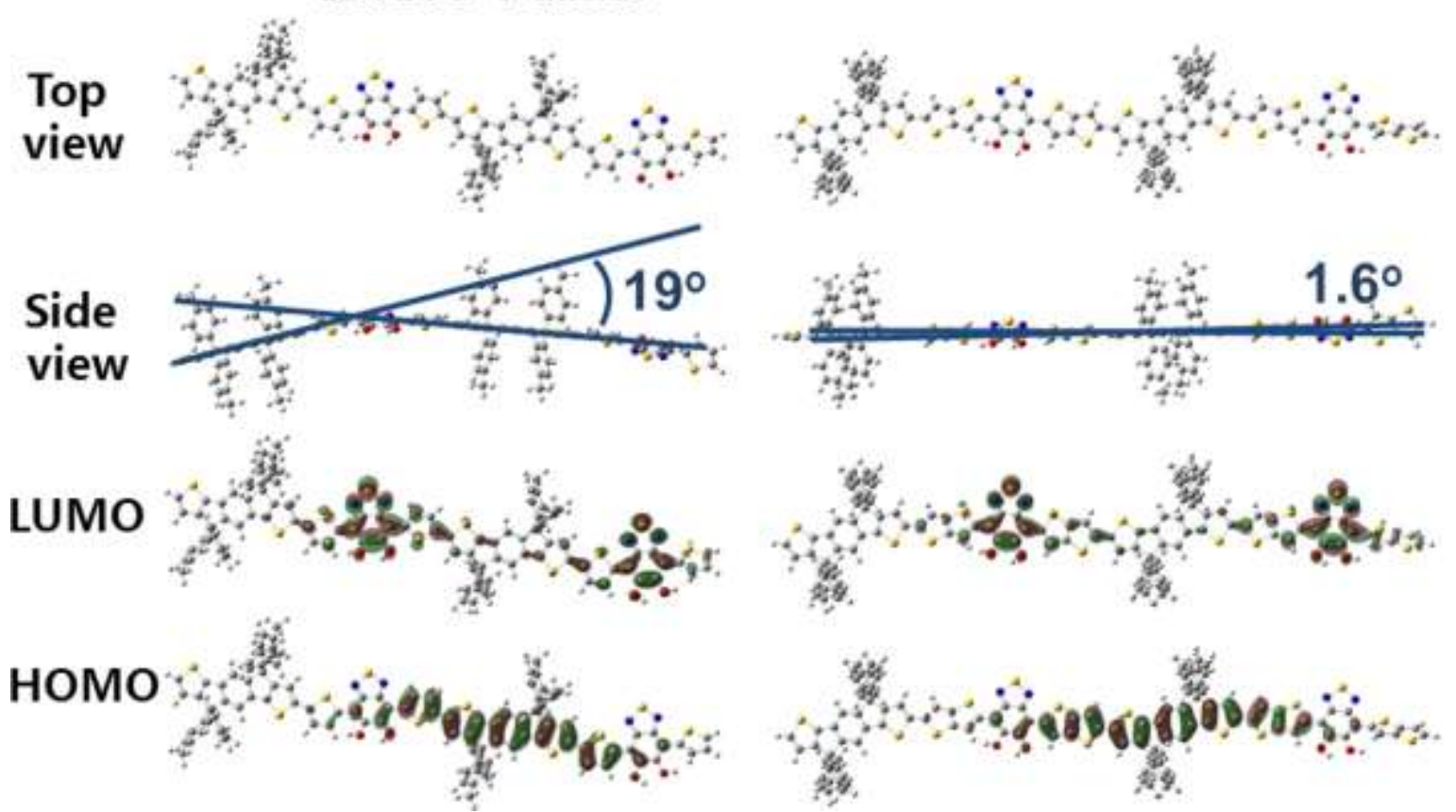

Figure 2. DFT-calculated LUMO and HOMO of the geometry optimized structures of analogous dimers of PIDTBTO-T (left), and PIDTBTO-TT (right). 

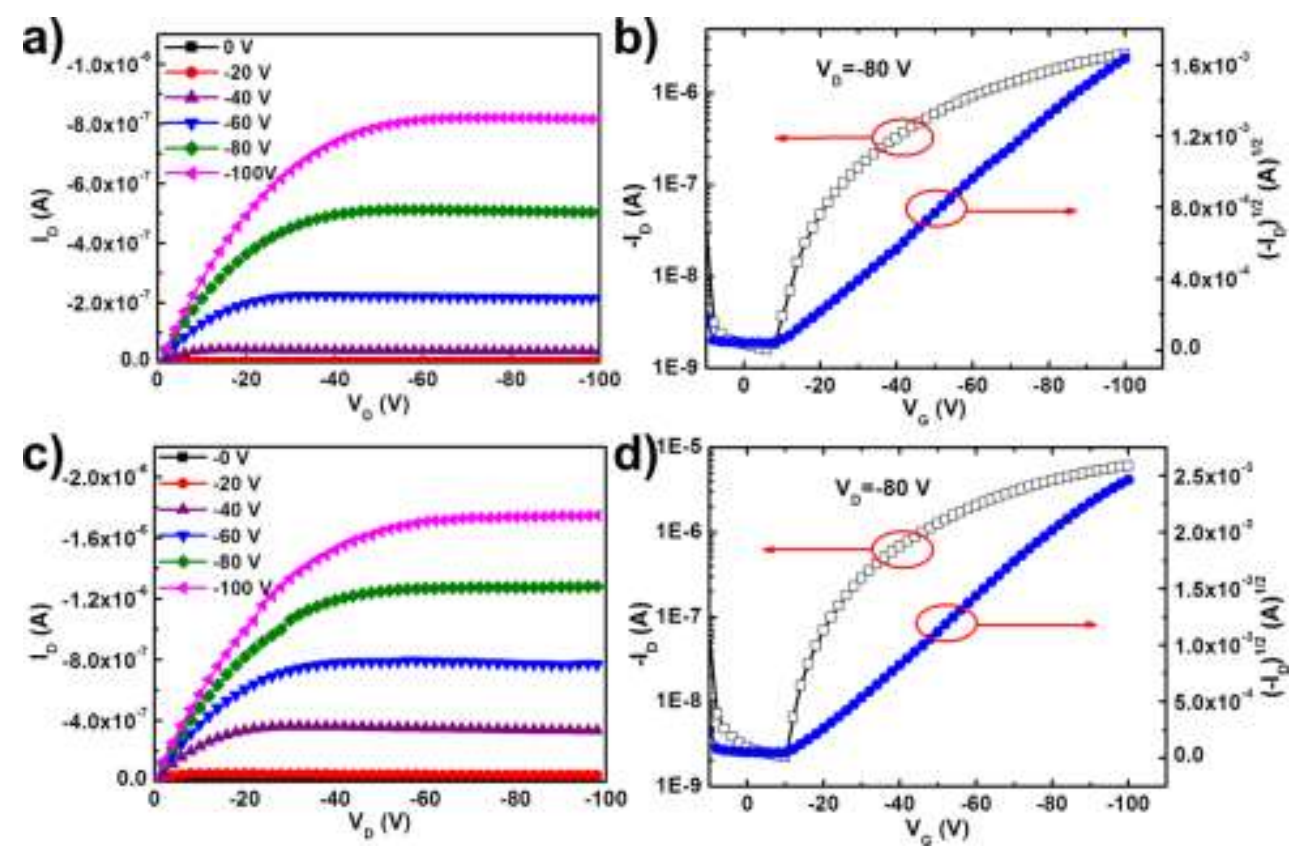

Figure 3. Typical output characteristics of OFETs based on PIDTBTO-T (a) and PIDTBTO-TT (c); and transfer characteristics of OFETs based on PIDTBTO-T (b) and PIDTBTO-TT (d). 

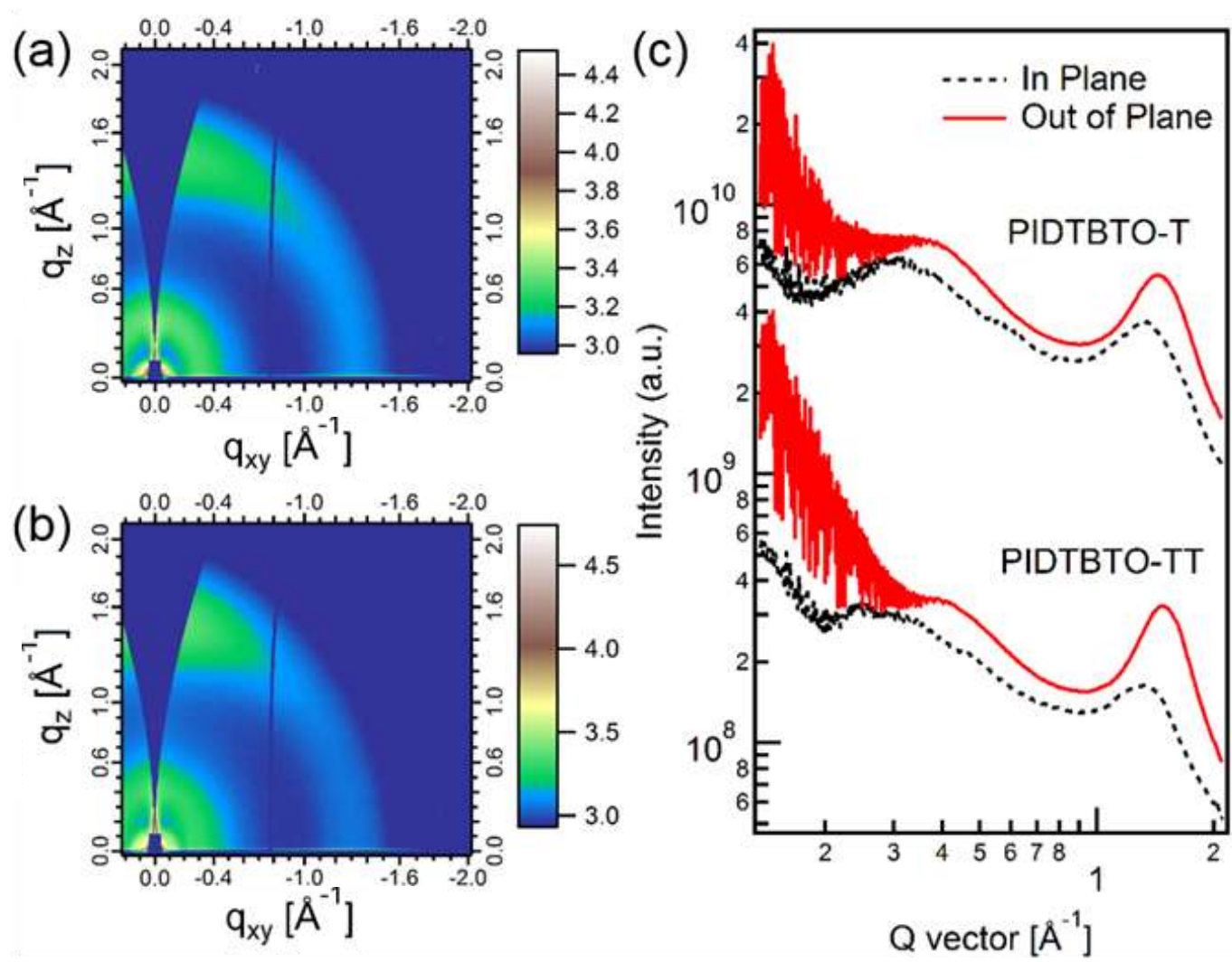

Figure 4. 2D GIWAXS patterns of spin-coated thin films of PIDTBTO-T (a) and PIDTBTO-TT (b), and the corresponding $\mathrm{1} \mathrm{D}$ line-cuts in the in-plane and out-of-plane directions $(\mathrm{c})$. 
a)
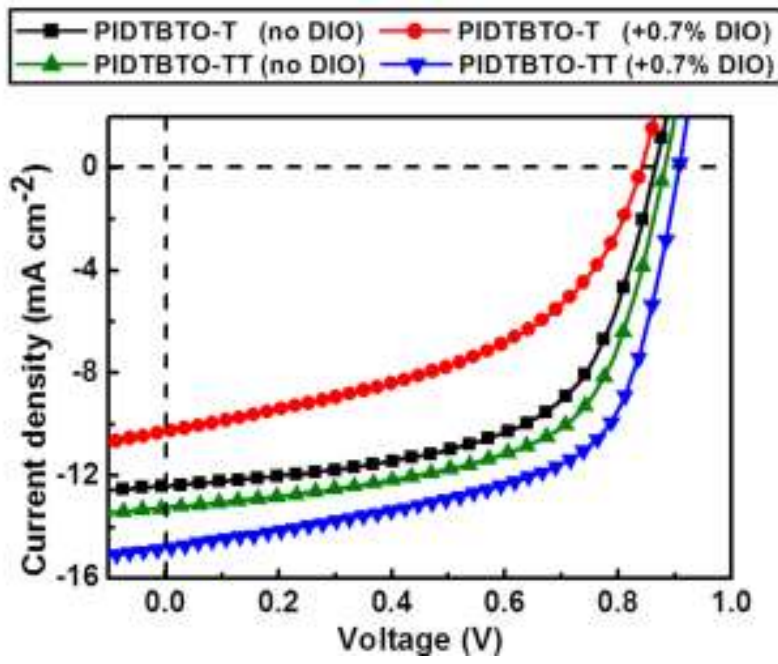

b) $\rightarrow-$ PIDTBTO-T (no DIO) $\rightarrow-$ PIDTBTO-T $(+0.7 \%$ DIO)

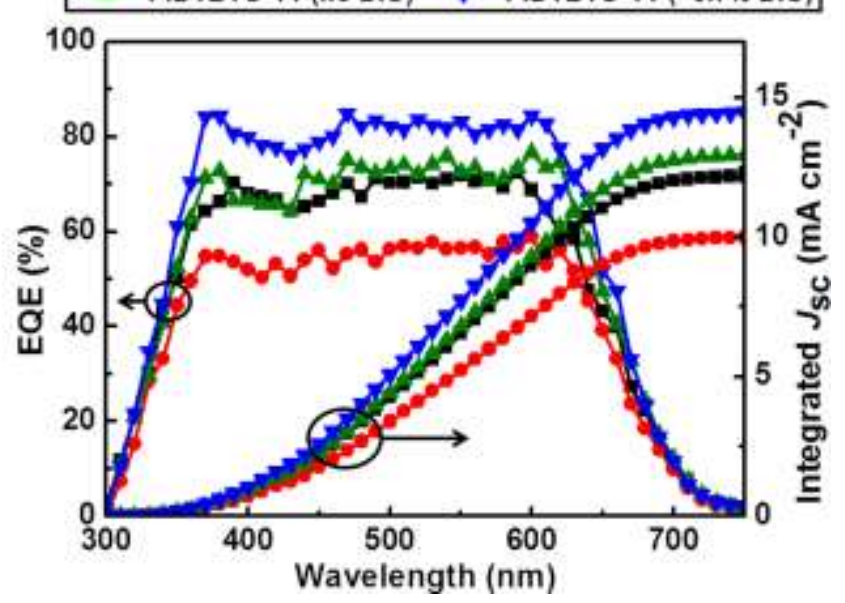

Figure 5. a) Current-voltage characteristics of PSCS fabricated with and without the DIO additive; b) EQE and corresponding integrated $J_{\mathrm{sc}}$ curves of PSCs fabricated with and without the DIO additive. 
a)

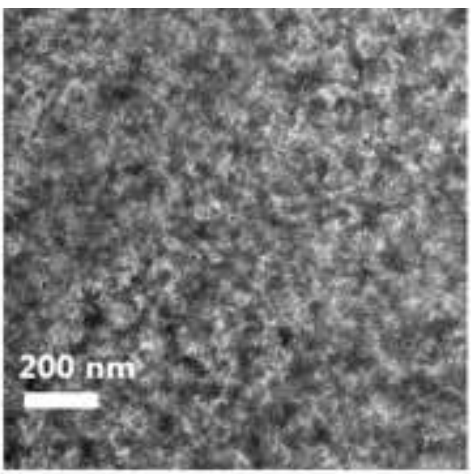

b)

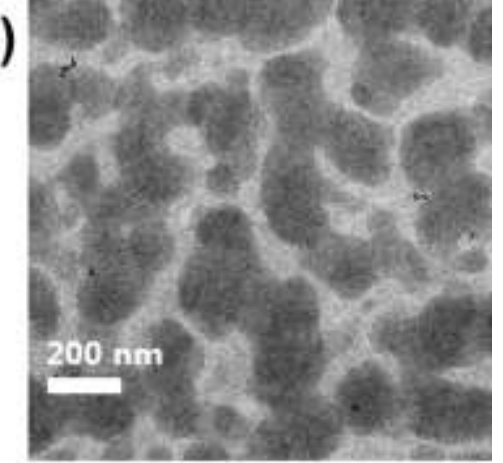

c)

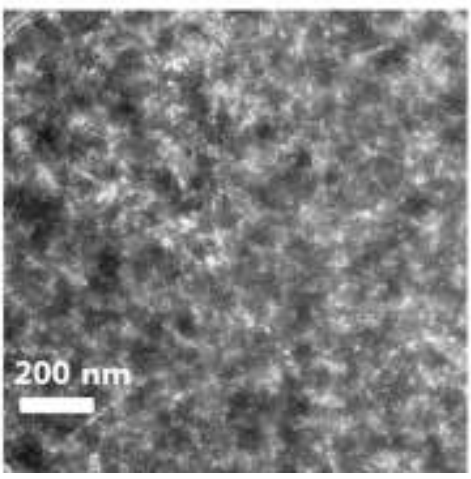

d)

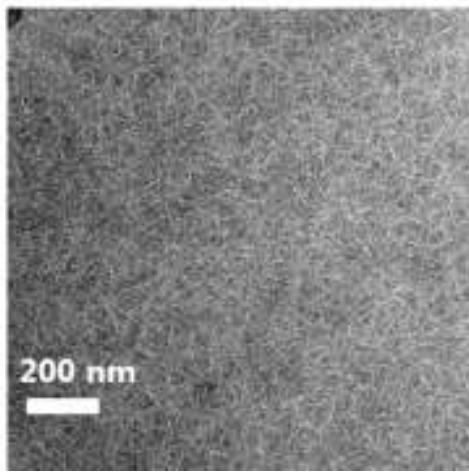

Figure 6. TEM images of PIDTBTO-T:PC ${ }_{71} \mathrm{BM}$ and PIDTBTO-TT:PC ${ }_{71} \mathrm{BM}$ without DIO $(\mathrm{a}, \mathrm{c})$ and with $0.7 \%$ DIO $(b, d)$. 
a)
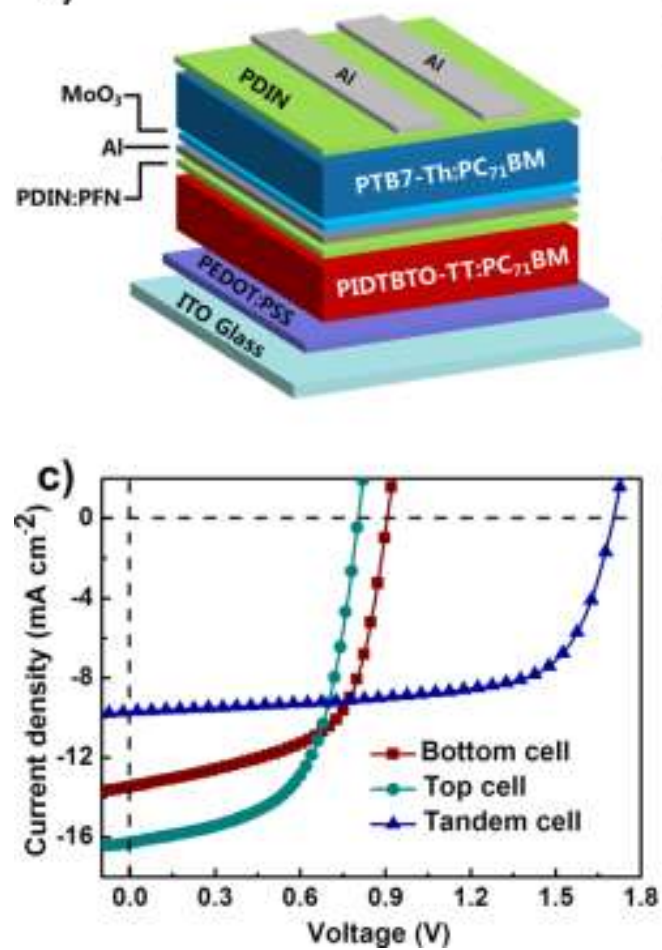

b)
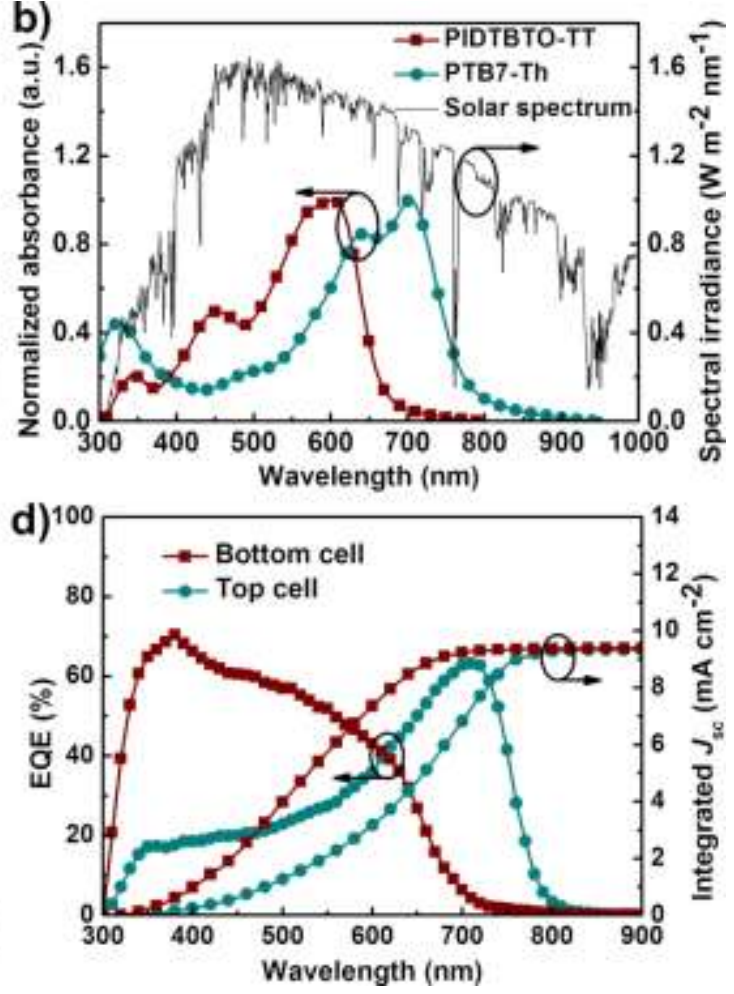

Figure 7. a) Device structure of the tandem PSC; b) Absorption spectra of PIDTBTO-TT, PTB7-Th and the solar spectrum; c) $J-V$ curves of the bottom (PIDTBTO-TT:PC ${ }_{71} \mathrm{BM}$ ), top (PTB7-Th:PC $\mathrm{P}_{71} \mathrm{BM}$ ) sub-cells and the tandem device under AM $1.5 \mathrm{G}$ illumination, $100 \mathrm{~mW} / \mathrm{cm}^{2}$; d) EQE and corresponding integrated $J_{\mathrm{sc}}$ curves of the top and bottom cells. 


\section{Biographies}

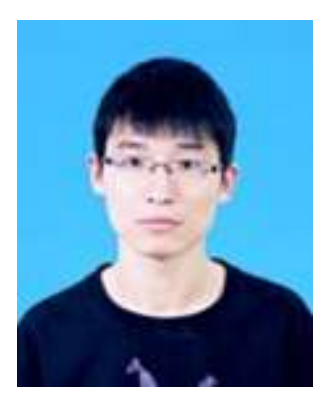

Yunlong Ma received his B.S. degree from Minjiang University in 2009, and M.S. degree in materials science and engineering from Fujian Normal University in 2012. He is currently pursuing his Ph.D. under the supervision of Prof. Qingdong Zheng. His research interests include the synthesis of organic semiconducting materials for polymer solar cells.

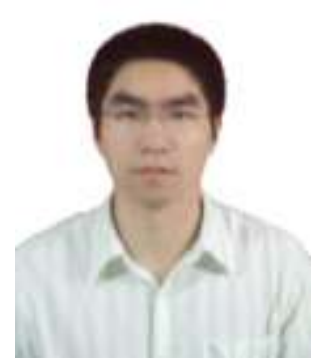

Shan-Ci Chen received his B.S. degree in chemistry from Xiamen University in 2005 and a Ph.D. degree in physical chemistry from Fujian Institute of Research on the Structure of Matter, Chinese Academy of Science in 2010. He is now an associate professor in Prof. Qingdong Zheng's group at the Fujian Institute of Research on the Structure of Matter, Chinese Academy of Sciences. Dr. Chen's interest involves design, synthesis, and characterizations of materials for various applications including organic field-effect transistors, organic solar cells etc.

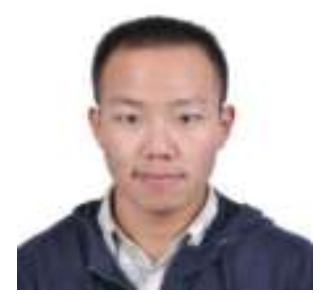

Zaiyu Wang received his B. Eng in Materials Science \& Engineering from Xi'an Jiaotong University in 2015 and joined Prof. Ma's group the same year. He is currently working on the morphology characterization of organic solar cells at Xi'an Jiaotong University as a graduate student.

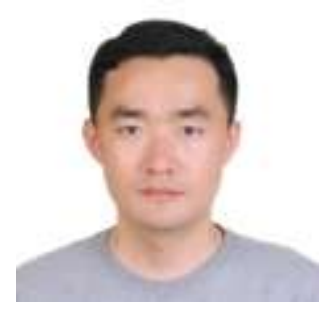

Wei Ma obtained his Ph.D. in Chemical Physics from the University of Pierre Marie Curie (Paris 6, France) in 2010 before moving to the Ecole Normale Superieure (Paris), France (2010-1011) and North Carolina State University (NCSU) as Postdoc Fellow. He joined the School of Materials Science Engineering at Xi'an Jiaotong University in 2014 as a Professor. His research interests include the use of soft/hard X-ray based techniques to unravel the relationship between film microstructure and device performance.

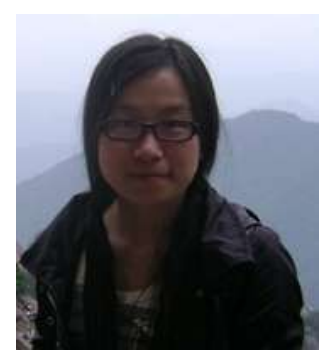

Jinyun Wang received her B. S. degree in education of chemistry from Fujian Normal University, China in 2006. And she got the M. S. and Ph. D degrees in theoretical and computational chemistry from Fujian Institute of Research on the Structure of Matter (FIRSM), Chinese Academy of Sciences in 2008 and 2011, respectively. After that, she serviced as an Assistant Professor in the State Key Laboratory of Structural Chemistry and Chemistry Division at FIRSM. Her research project is related to the theoretical study of the photophysical and electron-transport properties of the metallorganic complexes. 


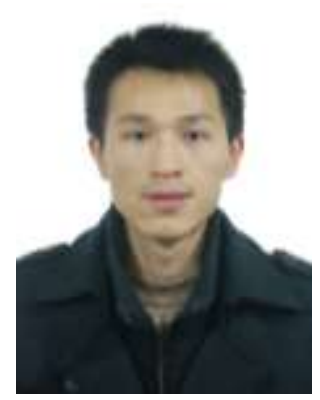

Zhigang Yin received his bachelor degree from Xi'an Technological University in 2008 and his master's degree in materials physics and chemistry from Fuzhou University in 2011. He then joined the Fujian Institute of Research on the Structure of Matter, Chinese Academy of Sciences (CAS), and became an associate professor in 2016. His research interests include optoelectronic materials, energy devices, and interfacial sciences.

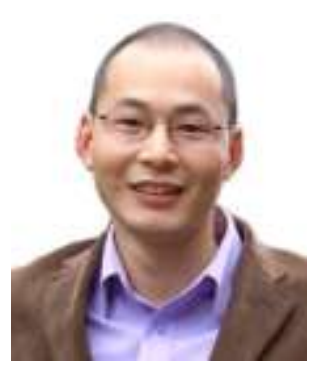

Changquan Tang received his B.S. degree from Jiangxi Normal University in 2007 and M.S. degree in organic chemistry from Central South University in China in 2010. He is currently pursuing his Ph.D. in the University of Chinese Academy of Sciences. His research interests focus on the synthesis and applications of photon-active materials.

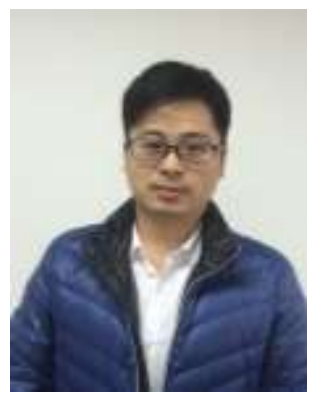

Dongdong Cai received his bachelor degree and Master's degree from Fujian Normal University in 2009 and 2012, respectively. He then joined the Fujian Institute of Research on the structure of Matter, Chinese Academy of Sciences. His research interests include organic semiconductor materials, organic solar cells, and organic field effect transistors.

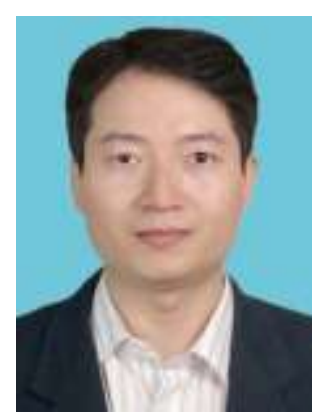

Qingdong Zheng received his B.S. degree in fine chemicals and his M.S. degree in applied chemistry from East China University of Science and Technology, China in 1998 and 2001, respectively. He obtained his Ph.D. degree in chemistry from the State University of New York at Buffalo, USA in 2005. After carrying out his postdoctoral research at the Johns Hopkins University, he joined the Fujian Institute of Research on the Structure of Matter, Chinese Academy of Sciences, and became a professor in 2010. His main interests focus on multifunctional molecular materials and devices and in particular on the fields of semiconducting materials and related interfacial materials for organic solar cells. He has published more than 80 peer-reviewed papers. He is serving as Associate editor of RSC Advances and as topical editor of Chinese Optics Letters. 